\title{
Manufacture of glass and mirrors from lunar regolith simulant
}

\author{
Juergen Schleppi ${ }^{1, *} \mathbb{D}$, Joseph Gibbons ${ }^{1}$, Alexander Groetsch ${ }^{2}$, Jim Buckman ${ }^{3}$, Aidan Cowley ${ }^{4}$, and
} Nick Bennett ${ }^{1}$

${ }^{1}$ Nano-Materials Laboratory, Institute of Mechanical, Process and Energy Engineering, School of Engineering and Physical Sciences, Heriot-Watt University, Edinburgh EH14 4AS, UK

${ }^{2}$ Institute of Mechanical, Process and Energy Engineering, School of Engineering and Physical Sciences, Heriot-Watt University, Edinburgh EH14 4AS, UK

${ }^{3}$ Energy, Geoscience, Institute of Petroleum Engineering, Heriot-Watt University, Edinburgh EH14 4AS, UK

${ }^{4}$ European Astronaut Centre, Human Spaceflight and Robotic Exploration, European Space Agency, Linder Hoehe, 51147 Cologne, Germany

Received: 10 August 2018

Accepted: 31 October 2018

Published online:

19 November 2018

(C) The Author(s) 2018

\begin{abstract}
Future planetary surface missions to the Moon or Mars, for example, can be augmented by the use of local materials, in order to reduce launch mass and expand mission capability. Using lunar regolith simulant and heating it within a susceptor-assisted microwave oven, it was possible to manufacture a variety of basaltic glasses. Furthermore, it was possible to shape these glasses by grinding and polishing the surface flat and smooth. Glasses manufactured from different lunar regolith simulants were coated with aluminium or silver, and the reflective properties of the resulting mirrors and uncoated surfaces were measured. It was shown that with a porous and/or smooth surface finish, mirrors could be made that reflect the incident solar light $(400 \mathrm{~nm}-1250 \mathrm{~nm})$ in-between $30 \%$ for the worst and $85 \%$ for the best samples. The same samples with uncoated surfaces showed to reflect less than $7 \%$ of incident solar light in the same wavelength range.
\end{abstract}

\section{Introduction}

Future exploration missions outlined in the ISECG's Global Exploration Roadmap-including human missions to the Moon and Mars-will have increasingly demanding payload requirements [1, 2]. Even with advances in the development of heavy lift systems, such missions will have significant mass constraints on the equipment flown into space. Resupply flights will be limited and in some cases impractical. In-Situ Resource Utilization (ISRU) has been suggested as a solution to this problem since the 1960s and recently new investigations on lunar regolith as a potential building material have been conducted [3]. Support for manned exploration missions using ISRU is a technology theme identified by

Address correspondence to E-mail: js79@hw.ac.uk 
ESA in its "ESA Space Exploration Strategy-2015" and NASA in its "NASA Strategic Space Technology Investment Plan-2015". Within these plans "Space Power and Energy Systems" and "Human Exploration Destination Systems" are areas that have been identified that can benefit from augmentation utilising ISRU. As a result, investigations into combining the need for local energy harvesting by utilising resources-by means of ISRU-are under investigation in this work.

So far no landing site for a lunar mission has been selected, and it is unclear what exact mineralogy the available raw material at any landing site will have. Hence, the ISRU processes in general should be capable of handling a wide variety of permutations of materials. Moreover, due to mass constraints, the systems used for manufacturing, transport and assembly of any mission augmenting item need to be relatively, simple, small and light.

The manufacturing approach presented herein uses a susceptor-based microwave heating method which should function on the lunar surface in a similar manner to how it does on Earth. Using this technology-in a first stage in Earth-like conditionsglass-like substrates were manufactured, polished and coated with reflective materials. This ultimately could lead to a mirror, manufactured of material found in situ on the lunar surface. A set of these mirrors can be arranged in an array to deflect incident sunlight to either an topically shadowed region or concentrate it onto a solar array. Other applications for these mirrors on the surface include solar furnaces, telescopes and thermal insulation/management.

Early work on microwave sintering of lunar soil was conducted in 2005, but suggested that lunar soil simulants are not ideal candidates for microwave sintering not least due to the absence of nanophase iron (3-10 mm) [4]. In 2013 computational modelling and experimental microwave processing of lunar regolith simulant showed that it is possible to use microwaves for processing and furthermore suggested the use of susceptors [5]. In 2014 and 2015 two more groups showed that microwaves can be used to sinter and melt regolith utilising microwaves [6, 7]. Also in 2015, a group of geoscientists determined that microwaves can be used to melt terrestrial andesite within 3-4 min [8], suggesting microwave heating to be an energy-efficient way of melting basaltic rocks. Most recently, in 2016 work on supporting long-term surface exploration on the Moon suggested to investigate susceptor-assisted microwave heating instead of direct microwave heating [9]. This would overcome the issues of regolith dependant susceptibility and hence inhomogeneity of heating, leading to thermal imbalance and ultimately to weak mechanical properties in the manufactured part [9]. This recent development leads to the research presented here on microwave manufacturing of glasses from lunar regolith simulant.

\section{Lunar regolith and simulants}

The Moon can generally be divided in two different areas, the mare areas which appear darker to the human eye and the highland areas which are brighter. Its surface is covered with a layer of fine dust, the so-called regolith which is up to $10 \mathrm{~m}$ thick on the highland surfaces and $5 \mathrm{~m}$ in the mare regions. Although the bulk part of the regolith is a fine grey soil, it also contains rock fragments from the bedrock [10-13]. In order to identify how regolith can be made useful for building glass-like substrates as a basis for solar conversion devices; chemical composition, grain size distribution and mineralogy of lunar regolith needs to be understood. (In particular, how these parameters might impact the manufacturing of such substrates.) Since real lunar regolith is not available for experimentation, available terrestrially sourced regolith simulants have been investigated and used for testing.

\section{Chemical composition of lunar regolith}

The average chemical composition of the lunar regolith in comparison with Earth's crust is shown in Table 1.

The composition shows that silicon, in the form of silicon dioxide, is the second most abundant element after oxygen for both, Earth and the lunar surface. However, none of the listed elements is found elementally pure on the lunar surface but in form of minerals. All elements occur in the chemically stable oxide form and purification (processes which are non-trivial) needs high amounts of energy for extraction. It is therefore neither practically nor economically viable for an initial base on the lunar surface to consider purification for augmentation. The abundance of silica, however, suggests that the raw 
Table 1 Average chemical composition of lunar surface regolith. Adapted from [68] and the most abundant elements in Earth's continental crust [69]

\begin{tabular}{lclc}
\hline Element & Regolith per cent of atoms $^{\mathrm{a}}$ & Regolith weight \% of oxides & Earth's crust weight \% \\
\hline $\mathrm{O}$ & 61.0 & - & 45.2 \\
$\mathrm{Si}$ & 16.3 & 45.0 & 27.2 \\
$\mathrm{Al}$ & 9.5 & 22.3 & 8.0 \\
$\mathrm{Mg}$ & 4.3 & 8.0 & 2.8 \\
$\mathrm{Ca}+\mathrm{K}$ & 6.0 & 15.5 & 6.8 \\
$\mathrm{Fe}$ & 2.3 & 7.6 & 5.8 \\
$\mathrm{Ti}$ & 0.3 & 1.1 & 0.9 \\
$\mathrm{Na}$ & 0.4 & 0.6 & 2.3 \\
Total & 100.1 & 100.1 & 99.0 \\
\hline
\end{tabular}

${ }^{a}$ Oxygen stoichiometrically determined [70] regolith might be used directly for manufacture of silica based glasses instead. The regolith composition shown in Table 1 shows typical elements other than silicon which are found in the lunar regolith mix, for example $\mathrm{Al}, \mathrm{Ca}$, or $\mathrm{Mg}$. These being additives to, for example soda lime glass on Earth, further support the argument of manufacturing glass from regolith.

\section{Lunar mineralogy and geology}

This section merely provides a general overview of the mineralogy and geology of the Moon based on the limited number of lunar regolith samples available on Earth. In-depth studies, in the form of prospecting missions and sample return missions, will need to be conducted once a landing site for a lunar base is selected. This is necessary since-looking at the data in Table 2-fluctuations between different landing sites can be significant and will have an impact on any ISRU application. The few examples in Table 2 already show variations of olivine content from 0.2 to $11.6 \%$. This, for example, will change the melting point of the regolith, since the ratio of different olivine minerals such as forsterite and fayalite will have an impact on that, along with variations in magnesium oxide and iron oxide content [14].

The geology and mineralogy of lunar regolith material were studied from the samples from the Apollo and other missions and are considered an approximate overview of the geology, geochemistry, geophysics and mineralogical compositions at the Apollo landing sites on the Moon [15-19]. A summary of the mineralogical composition is listed in Table 2 and shows that pyroxenes, plagioclase feldspars and olivines are the dominant minerals found on the lunar surface. Those mostly contain silicon and aluminium oxides plus lower quantities of iron, magnesium, calcium and sodium. Mineralogical studies [20-24] of lunar samples confirm this observation and thus match the geochemistry shown in Table 1.

\section{Regolith simulants overview}

By comparing the lunar regolith's chemical composition with the composition of Earth's crust (Table 1),
Table 2 Modal proportions (vol of minerals and glasses in soils from the Apollo

(A) sampling sites (90-20 $\mu \mathrm{m}$ fraction, not including fused soil and rock fragments).

Taken and modified from p. 123 in the Lunar Source Book [19] originally from $[11,71,72]$

\begin{tabular}{llllllll}
\hline Mineral & A-11 & A-14 & A-(H) & A-(M) & A-16 & A-(H) & A-(M) \\
\hline Plagioclase & 21.4 & 31.8 & 34.1 & 12.9 & 69.1 & 39.3 & 34.1 \\
Pyroxene & 44.9 & 31.9 & 38.0 & 61.1 & 8.5 & 27.7 & 30.1 \\
Olivine & 2.1 & 6.7 & 5.9 & 5.3 & 3.9 & 11.6 & 0.2 \\
Silica & 0.7 & 0.7 & 0.9 & - & 0.0 & 0.1 & - \\
Ilmenite & 6.5 & 1.3 & 0.4 & 0.8 & 0.4 & 3.7 & 12.8 \\
Mare glass & 16.0 & 2.6 & 15.9 & 6.7 & 0.9 & 9.0 & 17.2 \\
Highland glass & 8.3 & 25.0 & 4.8 & 10.9 & 17.1 & 8.5 & 4.7 \\
Other & - & - & - & 2.3 & - & - & 0.7 \\
Total & 99.9 & 100.0 & 100.0 & 100.0 & 99.9 & 99.9 & 99.8 \\
\hline
\end{tabular}

$H$ highland, $M$ mare 
it can be noticed that all major abundant elements can be found on both celestial bodies. Therefore, finding a suitable chemically analogue material (similar to lunar regolith) on Earth is possible. On Earth, simulants are used to simulate the lunar regolith which is necessary since only about $400 \mathrm{~kg}$ of actual lunar regolith is available [25-27]. Therefore, evaluations of different simulant types have been conducted [28-30] and a variety of basaltic sands found on Earth have shown to be adequate simulants with respect to chemical composition.

The lunar regolith simulant most often used in publications and practical validations in the past is a simulant called JSC-1A, which, however, is not being produced anymore and was replaced with a second version, JSC-2A. Both have a similar chemical composition but JSC-2A is more advanced, since it is produced by using an apparatus developed by Zybek Advanced Products described in [31]. This way of manufacturing delivers a better representation of grain size and grain geometry of the actual lunar regolith as well as it forms impact glasses in the mix. Impact glasses are commonly found on the lunar surface (Table 2) and are created by micro-meteoroids hitting the lunar surface, partially melting regolith and spreading it over the surface. An amount as high as more than $20 \%$ of glass is not commonly found in terrestrial basalts which is why JSC-2A is a more advanced simulant for testing the process described in this work.

Although JSC-2A seems to be the most sophisticated lunar regolith simulant, a variety of regolith simulants have been used for this study to account for chemical and geological differences of the actual lunar material. The four used simulants are depicted in Fig. 1 and are sourced from:

- JSC-2A (Mare) and LHT-3M (highland type simulant) both procured from Zybek Advanced Products in Westminster (CO), USA.

- FJS-1 (Mare) procured from CSP Japan, Inc in Tokyo, Japan.

- EAC-1 (Mare) provided by the European Astronaut Centre in Cologne, Germany.

These simulants have been identified as the most important and relevant simulants because of their geochemical, mineralogical and geometrical differences as well as availability of literature. The EAC-1 simulant is a newly developed simulant by ESA's
Astronaut Centre, and it is sourced from a quarry (Eifel region) near Cologne, Germany.

\section{Chemical composition of regolith simulants}

The chemical composition of the four simulants used (as provided by the suppliers) is listed in Table 3. It shows a similar silica content across all simulants with a maximum of approximately $49 \%$ (FJS-1) and a minimum of approximately $44 \%$ for EAC-1. Significant differences can be seen in aluminium, magnesium and iron oxide content with fluctuations of $12.6-24.4 \%$ for $\mathrm{Al}_{2} \mathrm{O}_{3}, 3.84-11.9 \%$ for $\mathrm{MgO}$ and $4.16-13.07 \%$ for the sum of both iron oxides types $\left(\mathrm{FeO}+\mathrm{Fe}_{2} \mathrm{O}_{3}\right)$. The variation of these oxides is expected to have an impact on the melting temperature, and thus, the processing temperature required for manufacturing glasses which will likely also impact annealing temperatures and annealing times.

The chemical composition of the raw regolith is also expected to have an impact on optical properties, of glass manufactured from regolith, such as colour and reflectivity. Although achieving an optically transparent glass might be desirable, it is more likely for the manufactured glass to be coloured dark brown/black/red because of the iron mineral content such as haematite $\left(\mathrm{Fe}_{2} \mathrm{O}_{3}\right)$ or green due to trace elements like chromium. Hence, before considering manufacture of optical transparent glass, a method of manipulating the mineral mix needs to be found in order to remove certain minerals that influence the colour of the melt.

\section{Glass manufacturing}

Glass is, amongst many other different applications, commonly used as a substrate for semiconductor devices on Earth. Having glass as raw material available in space can have a broad variety of applications, for example as substrate or backplate for semiconductor devices or electronics, windows, pipes/tubes, fibres, formed objects, thermal insulation foams and low-density aerobraking heat shields. In 1979 it was acknowledged that a wider variety of glass can be useful on the Moon [32] and, for example in 1986, processing of lunar materials by means of microwave melting has been investigated [33]. Therefore, determining which terrestrial glass 
Figure 1 Four types of lunar regolith used: EAC-1 (top left), JSC-2A (top right), LHT$3 \mathrm{M}$ (bottom left), FJS-1

(bottom right). Scale bar is in $\mathrm{cm}$.

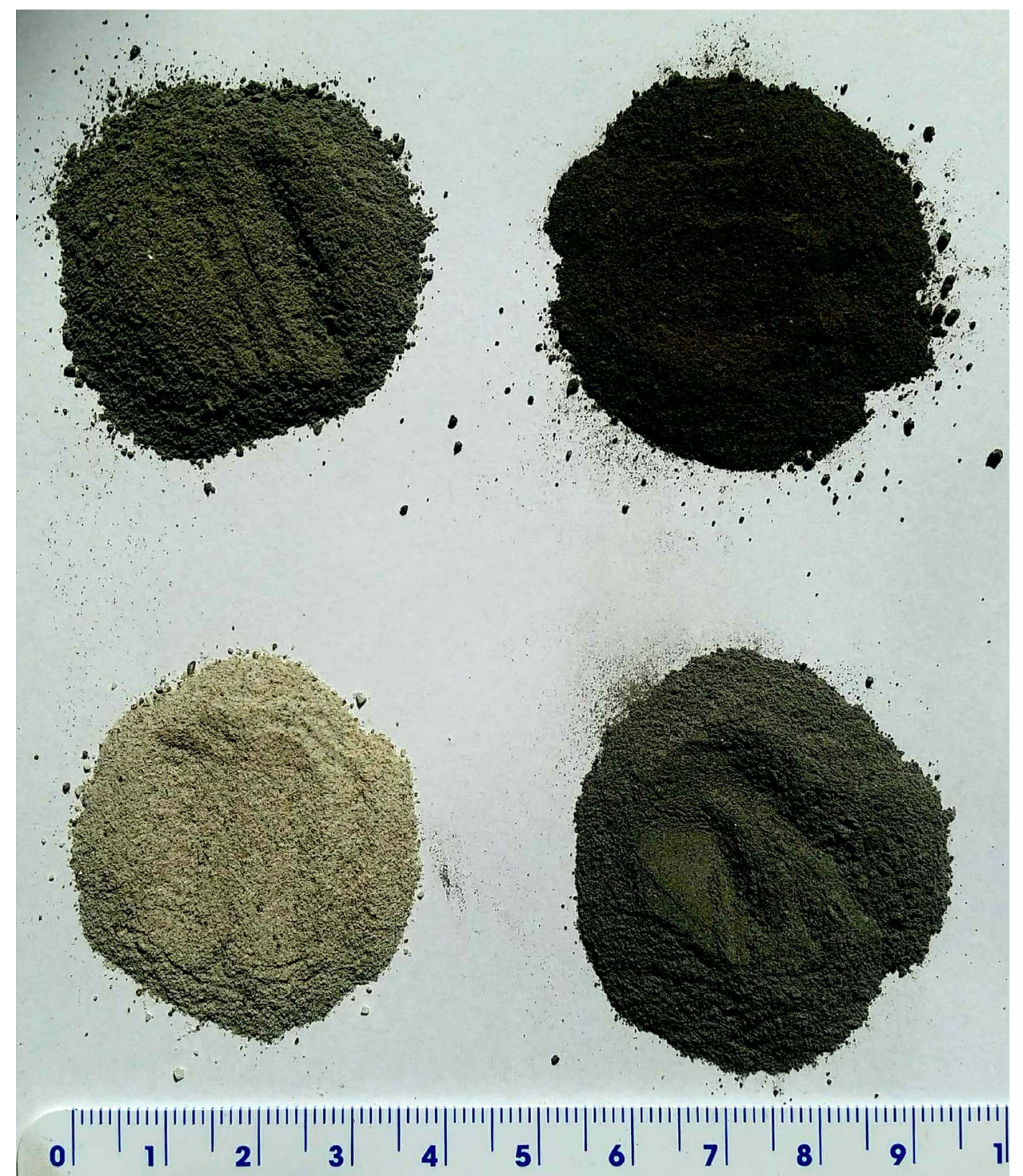

material is limited to basaltic sand. Hence, no pure additives or fining agents are available to add to the glass mix and therefore the properties of the glass depend on the composition of the basaltic sand only.

\section{Basaltic glass}

Basaltic glass is formed by melting basaltic material and occurs naturally on both Earth and the Moon. The most prominent naturally occurring example on Earth is obsidian. Igneous rock occurring in the form of obsidian is a natural glass which forms due to rapid cooling or quenching of hot volcanic lava. Obsidian is glass like in appearance and harder than regular soda lime glass. It is usually very silica rich (approximately $65-80 \%$ ), and the usual colour of 
Table 3 Compositional information of utilised regolith simulants

\begin{tabular}{lcllr}
\hline Oxide & JSC-2A & LHT-3M & EAC-1 & FJS-1 \\
\hline $\mathrm{SiO}_{2}$ & 47.50 & 46.70 & 43.70 & 49.14 \\
$\mathrm{Al}_{2} \mathrm{O}_{3}$ & 15.00 & 24.40 & 12.60 & 16.23 \\
$\mathrm{Fe}_{2} \mathrm{O}_{3}$ & 3.50 & 4.16 & 12.00 & 4.77 \\
$\mathrm{FeO}$ & 7.25 & - & - & 8.30 \\
$\mathrm{MgO}$ & 9.00 & 7.90 & 11.90 & 3.84 \\
$\mathrm{CaO}$ & 10.50 & 13.60 & 10.80 & 9.13 \\
$\mathrm{Na}_{2} \mathrm{O}$ & 2.75 & 1.26 & 2.90 & 2.75 \\
$\mathrm{~K}_{2} \mathrm{O}$ & 0.80 & 0.08 & 1.30 & 1.01 \\
$\mathrm{TiO}_{2}$ & 1.50 & 0.41 & 2.40 & 1.91 \\
$\mathrm{MnO}$ & 0.18 & 0.07 & 0.20 & 0.19 \\
$\mathrm{P}_{2} \mathrm{O}_{5}$ & 0.80 & 0.15 & 0.60 & 0.44 \\
$\mathrm{Total}$ & 98.78 & 98.73 & 98.40 & 97.71 \\
\hline
\end{tabular}

obsidian is black. It can, however, also naturally occur in brown, red, green, grey or yellow varieties, most of which are influenced by different iron oxide contents [34]. The forming of glass from lunar regolith simulant is hence considered to be similar.

From the list of minerals abundant on the Moon (Table 2), it can be seen that glass found in the lunar Mare regions can get as high as $17 \mathrm{vol} \%$ and as low as less than $1 \mathrm{vol} \%$. Similarly, the highland glass volume per cent content can be observed in-between 5 and $25 \%$. Since, in glass fabrication, the content of recycled glass versus new material (e.g. sand) can be crucial to lowering process temperatures and hence the energy required to melt the material, it will be important to gain a better understanding on the role of basaltic glasses content in regolith. In particular, what impact the basaltic glass content in the start mix has on the manufacturing process.

Studies focused on lunar glass are rare [35] and usually focused around the geological history of the Moon rather than the properties of the actual glass. Other available studies on basalt glass most often focus on terrestrial volcanic basalts [36], mid-ocean ridge basalts [37] or crystallisation behaviour [38]. More specifically, basaltic glass has been studied on Earth for a variety of applications such as recycling of sewage sludge [39], recycling of residues of basaltic quarries and ceramic wastes [40] as well as sintering it into thermal insulation blocks [41] or its behaviour by adding additives [42]. Understanding the composition, structure and processing of lunar basalt is vital in gaining a better understanding of the melting temperature, cooling and annealing behaviour as well as the crystallisation of basaltic glass. Hence, the behaviour of lunar basaltic glasses compared to terrestrial glasses will need further investigation.

\section{Microwave processing}

Microwave processing is a widely used technology in a variety of terrestrial applications [43,44] nowadays, not at least due to its comparable low power consumption. The effect of microwaves on rocks, metals, silica sand and ceramics has been of recent interest [45-52] and is identified as a prime candidate for lunar regolith processing. Utilising a susceptor in microwave processing is called susceptor-assisted microwave heating [53] which has been used, for example, for the activation of silicon dopants [54] before. Utilising a susceptor-assisted approach to microwave processing regolith has the advantage that the process (compared to regular microwave processing) becomes more independent of the regolith composition. Differences in, for example iron oxide content, can influence processing time or processing temperature. Therefore, using a susceptor as a passive heating element (heated by the microwaves) makes microwave processing more universally applicable and independent of the regoliths' composition. The disadvantage of this addition to the process is that universal applicability is traded for power efficiency, since the losses of a susceptor-assisted heating process are higher than those of regular microwave heating.

A non-susceptor-assisted microwave heating concept, used as an ISRU technology, is described in [6]. A robot carrying a microwave heating chamber fed by a funnel, when regolith is entered through the funnel it is heated while sliding down and then, by moving along the lunar surface, released on the ground and liquid regolith cast onto the lunar surface. This conceptual idea is supported by investigations on suitability of microwave processing for long-term missions [9], microwave sintering of regolith [4, 7] and simulations of dielectric behaviour of regolith $[5,55]$. All showing that it seems possible to build as system similar to the one proposed by [6]. As suggested by [9], this work explores the possibility of expanding microwave heating capabilities by using a susceptor-assisted heating process to manufacturing basaltic glasses from lunar regoliths.

The method used to manufacture different batches of basaltic glass and basaltic glass mirrors from lunar 
regolith simulant is a susceptor-assisted microwave heating system schematically depicted in Fig. 2. The schematic shows rotationally symmetric microwave kiln lined with a susceptor material and a crucible placed in the centre. Microwaves hit the susceptor material which then in return starts radiating in the infrared spectrum. This microwave kiln was utilised in combination with a commercially available $2.5 \mathrm{GHz}$ microwave oven with a maximum operating power of $1 \mathrm{~kW}$. Since microwave processing of material happens at relatively high temperatures $\left(>1100{ }^{\circ} \mathrm{C}\right)$, high-temperature materials like carbon or silicon carbide $[56,57]$ need to be used as crucibles, both of which are also excellent susceptor materials themselves and therefore support the heating process.

Exact processing temperatures of the liquefied regolith could not be determined since necessary emissivity values were not available at that time. The temperature was therefore estimated using an emissivity value of $\varepsilon=0.90$ (constant for all temperatures above $1200{ }^{\circ} \mathrm{C}$ ). With this value, regolith temperatures of around $1400{ }^{\circ} \mathrm{C}$ could be measured in the spectral range from $2.0 \mu \mathrm{m}<\lambda<2.6 \mu \mathrm{m}$ and $8 \mu \mathrm{m}<\lambda<12 \mu \mathrm{m}(\lambda=$ wavelength $)$. The used setup has further more shown that it is capable of heating regolith independent of its composition since it was capable of heating and melting all four types of regolith simulant chosen. The flexibility with respect to the raw material is considered to be a result of using the susceptor-assisted heating approach rather than the direct approach reviewed by [9] or used by [6].

\section{Mirror manufacturing}

Understanding basalt glass manufacturing first is essential for manufacturing mirrors on the lunar surface since a good quality glass is key for manufacturing a good quality mirror.

Producing mirrors requires a substrate and a reflective material to be deposited on the surface. Most commonly aluminium is used for this purpose. Aluminium has high reflectivity $(\approx 90 \%)$ in the whole visible light spectrum, whereas silver is significantly worse below $400 \mathrm{~nm}$ [58]. The typically required aluminium layer thickens $\left(n_{\mathrm{Al}}\right)$-to achieve best reflection characteristics-for a mirror is $\approx 100$ $\mathrm{nm}$. For a surface area (A) of $100 \mathrm{~m}^{2}$ and a density $\left(\rho_{\mathrm{Al}}\right)$ of $2700 \mathrm{~kg} / \mathrm{m}^{3}$ [59], this implies a mass of $27 \mathrm{~g}$ of $99.999 \%$ purified aluminium would be sufficient to manufacture a mirror surface area of $100 \mathrm{~m}^{2}$ on the Moon. Even considering losses during this process the amount of high grade aluminium that needs to be purified on Earth and flown to the Moon is in the order of less than $1 \mathrm{~kg}$ and is hence deemed a viable approach to augmenting a lunar surface mission.

\section{Coating materials}

Looking at four different potential mirror coating materials ( $\mathrm{Al}, \mathrm{Ag}, \mathrm{Au}$ and $\mathrm{Cu}$ ) and how much light they reflected for a wavelength spectrum of $0.2-10 \mu \mathrm{m}$, it can be observed that all materials reflect about $70-90 \%$ of the light for wavelengths above $1.1 \mu \mathrm{m}$. Aluminium reflects the highest, with on average of more than $90 \%$ reflected light over the entire wavelength range (from 0.2 to $10 \mu \mathrm{m}$ ). Hence, aluminium seems to be the most likely choice for a coating which aims at reflecting as much light as possible. Although coating materials like silver may
Figure 2 Cross section of a cylindrical-shaped microwave kiln under operating conditions. (a) Crucible, (b) susceptor material. Here: magnetite-graphite mix (c) alumina fire brick insulation.

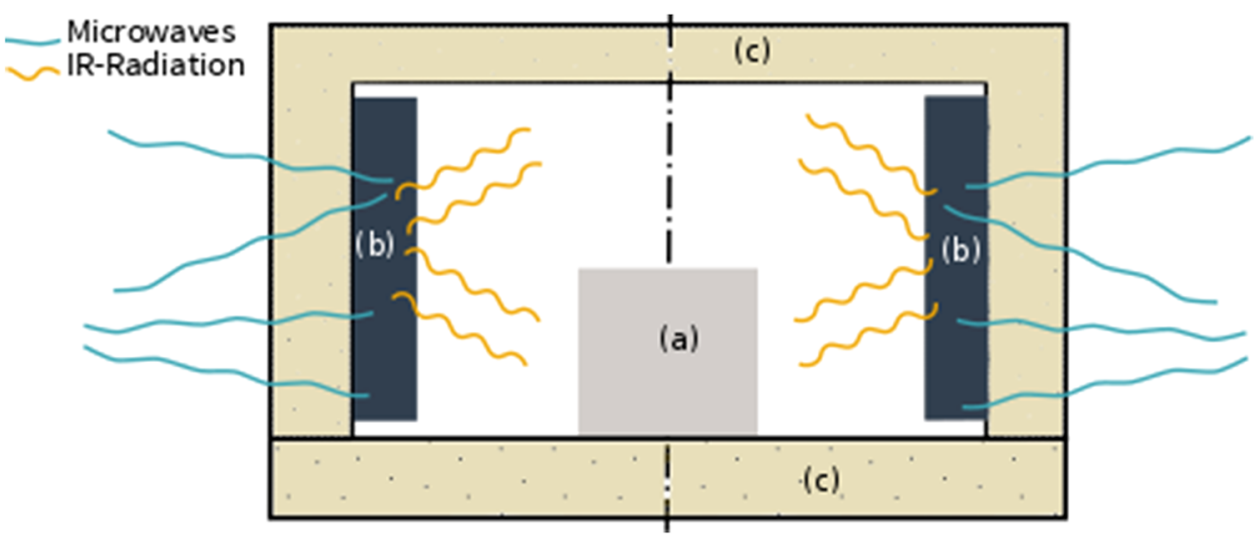


be advantageous compared to aluminium since they reflect a few more per cent of the wavelength spectrum in the infrared range, the ultimate decision for the coating material will hence need to be decided on the actual application the mirror is used in.

However, the selection of the coating material will not necessarily only focus on maximum reflection but might also be, for example, tailored to the absorption spectrum of a (multijunction) solar cells, which could be used in combination with mirrors in a solar concentrator setup. Suitable literature for tailoring the reflected wavelength range can be found in [60-62].

\section{Coating techniques}

To manufacture a mirror on top of a basaltic glass plate made from regolith, thin film deposition methods shall be utilised. The available technologies can be divided into two groups physical vapour deposition (PVD) and chemical vapour deposition (CVD). The chosen technique for this project is PVD, which evaporates or sputters a source material, producing a gaseous plume or beam that deposits a film, on a substrate, whereas thermal evaporation evaporates the base material using a resistive heating element. Typically, the raw material is placed into a source like a tungsten boat and temperature is increased to facilitate evaporation of the material. PVD is usually done under vacuum conditions to avoid gases from reacting (e.g. oxidising) with materials such as aluminium. On the lunar surface a high-quality vacuum is already existing which would allow for an even more simplistic version of an traditional evaporator system to be built. Due to its simplicity and likelihood to work on the lunar surface, thermal evaporation is therefore considered the best option for coating mirrors on the Moon's surface.

\section{Basalt glass and basalt mirror samples}

Experiments have been conducted in two separate batches. The first was an initial test using only two different simulants, JSC-2A and EAC-1, and it was conducted to determine the best manufacturing conditions with respect to reflective properties of the final substrate. For the second batch all four simulants (JSC-2A, LHT-3M, FJS-1 and EAC-1) have been utilised and processed at the $1000 \mathrm{~W}$ power setting of the microwave oven. An overview of all samples manufactured and measured is listed in Table 4.

The table shows simulant type used, heating times and weight before heating for each sample. For the second batch additionally the weight difference before and after heating has been recorded. Heating times for all but one sample was $40 \mathrm{~min}$ or less. Only the sample made of LHT-3M needed an heating time of $65 \mathrm{~min}$ since it was not fully melted after $40 \mathrm{~min}$.

The samples' ID is shows a combination of simulant type, batch and sample number (batch 1 ). Since in batch 2 there was only one sample of each regolith simulant, the sample number is dropped for the second batch of samples. For example, sample EAC-I3 is made of EAC-1 ("EAC") manufactured in batch 1 ("I") and was the third sample produced (" 3 ").

\section{Heating and shaping}

Both test batches have been manufactured using the susceptor-assisted microwave heating process, using graphite crucibles with a cavity of $45 \times 24 \times 10 \mathrm{~mm}$. This leads to samples with variable sizes ranging from approximately $22 \mathrm{~mm}$ in width, 8-12 $\mathrm{mm}$ height and 38-42 $\mathrm{mm}$ in length. Samples are shown in Fig. 3 and mostly form rectangular-shaped glass blocks similar in size to a domino brick. The following describes differences between samples and batches.

\section{Heating and shaping batch 1}

The first 5 (batch 1) glass samples were prepared by placing 5 times, $15 \mathrm{~g}$ of unaltered lunar regolith simulants into the graphite crucibles. Two samples were manufactured of JSC-2A and three of EAC-1. After filling the crucibles with simulant, they were entered into the microwave kiln and heated in air atmosphere. Details on heating times are listed in Table 4. All samples but one (JSC-I-2) were manufactured using a fusing method where the sample remained in the crucible for the whole process. The JSC-I-2 sample was manufactured by heating the material in a first crucible and then casting it into a second, preheated $\left(560^{\circ} \mathrm{C}\right)$ crucible of the same size. The second crucible was preheated and kept in an electric-heated kiln next to the microwave oven. The only other difference for how samples were manufactured was that for sample EAC-I-1, the cold EAC-1 
Table 4 Overview of batches 1 and 2 samples

\begin{tabular}{|c|c|c|c|c|c|}
\hline Sample ID & Simulant & Time $(\min )$ & Weight before heating (g) & Weight after mass (g) & Delta mass $(\mathrm{g})$ \\
\hline EAC-I-1 & EAC-1 & 20 & 15.00 & - & - \\
\hline EAC-I-2 & EAC-1 & 30 & 15.00 & - & - \\
\hline EAC-I-3 & EAC-1 & 15 & 15.00 & - & - \\
\hline JSC-I-1 & JSC-2A & 15 & 15.00 & - & - \\
\hline JSC-I-2 & JSC-2A & 40 & 15.00 & - & - \\
\hline EAC-II & EAC-1 & 30 & 14.97 & 14.51 & -0.46 \\
\hline LHT-II & LHT-3M & 65 & 19.97 & 19.86 & -0.11 \\
\hline FJS-II & FJS-1 & 30 & 15.11 & 14.98 & -0.13 \\
\hline JSC-II & JSC-2A & 30 & 15.04 & 15.07 & +0.03 \\
\hline
\end{tabular}

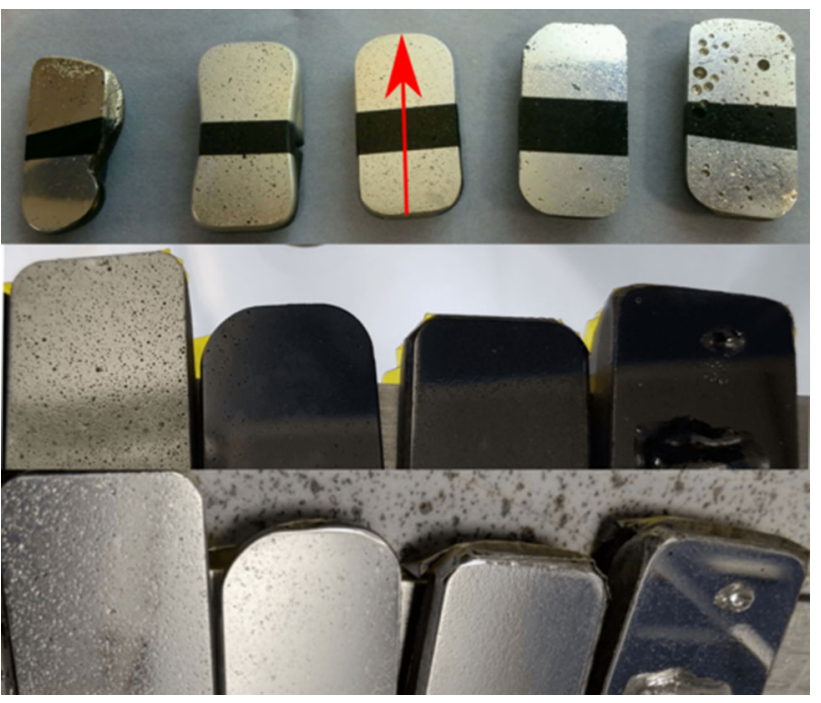

Figure 3 Batch 1 samples (top) after deposition of aluminium and silver. The top is coated in silver and the bottom part in aluminium. Samples from left to right: JSC-I-2, JSC-I-1, EAC-I-3, EAC-I-2, EAC-I-1. Batch 2 samples before (middle) and after (bottom) aluminium deposition, centre is left uncoated. Samples from left to right: LHT-II, EAC-II, FJS-II, JSC-II. The arrow in the top part indicates the position and direction, and the surface roughness measurements were recorded.

simulant was placed onto a tungsten sheet which lined the bottom of the graphite crucible.

After heating all samples for the times indicated in Table 4, they were removed from the microwave kiln and introduced in a second, electric-heated kiln at $560^{\circ} \mathrm{C}$. After introducing the samples into the kiln, the kiln was switched off and the samples were allowed to cool to room temperature within $2 \mathrm{~h}$. This process was kept constant for all samples and was supposed to release the inner thermal stress that has been built up inside the samples during heating. This should improve strength and durability to a point where the samples would not shatter any more. For lower and/or shorter annealing times, it could be observed that the samples would shatter even when not touched or moved. Since the manufactured samples where never heavier than $20 \mathrm{~g}$ the cooling and annealing times could be rather short (order of an hour) as well as annealing temperatures required seemed to be best around $560{ }^{\circ} \mathrm{C}$. Due to non-existent convection forces on the Moon itself, the only heat transfer mechanisms left are conduction and radiation. Hence, cracking on lunar produced samples may be less an issue, since slower cooling rate intrinsic to the lunar environment. It is concluded from those experiments that for up-scaling this process, it will be required to conduct a study on the behaviour of basaltic glass cooling, especially under lunar-like conditions.

\section{Heating and shaping batch 2}

For the second batch, four different simulants were utilised (overview in Fig. 4). In all cases the samples remained in the crucible they were melted in and were not cast. Heating times could be kept the same for all but one simulant, the LHT-3M showed to have a higher melting point than the other three simulants. It was attempted to compensate for this higher melting point by increasing the heating time. The weight loss or gain of the samples was very little in all cases but one, the EAC-II sample lost more than $3 \%$ of its weight during heating. This is very likely due to the release of water contained in the simulant. 


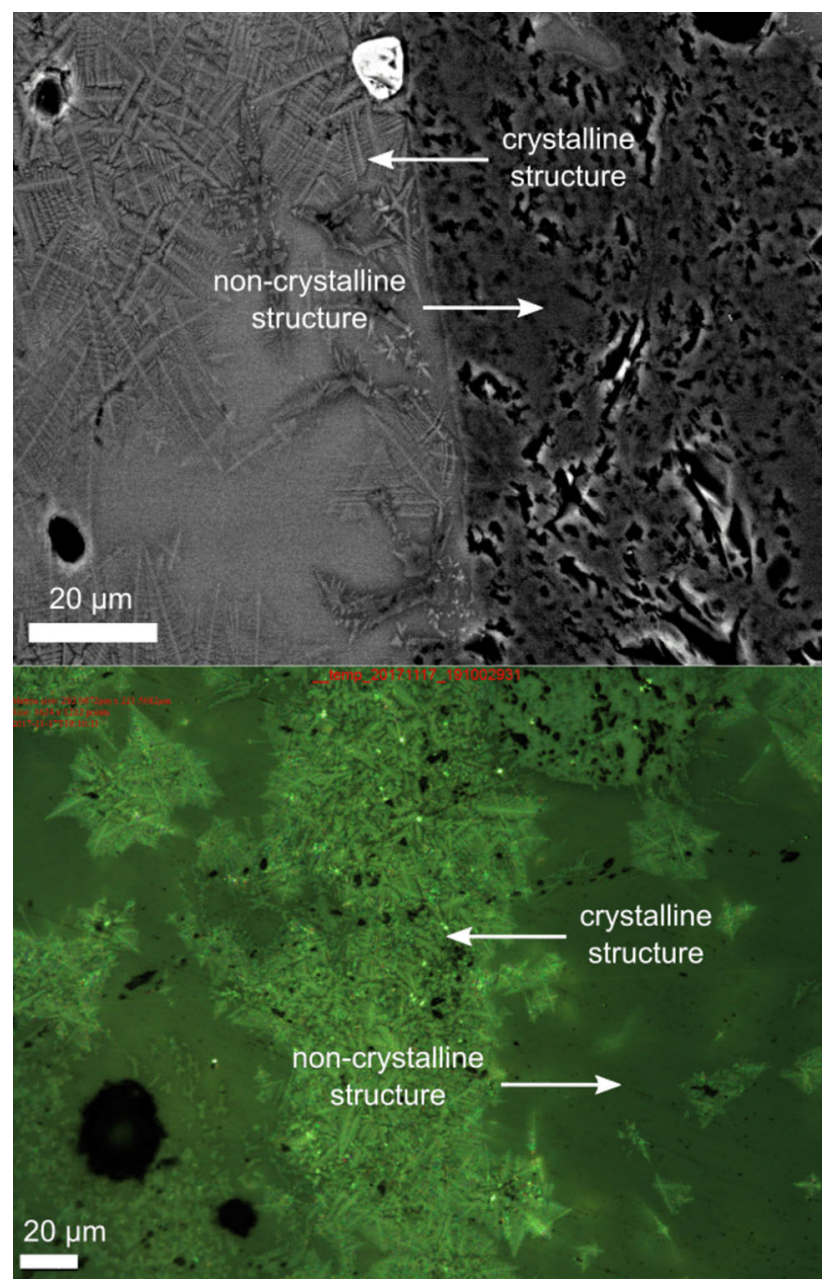

Figure 4 SEM images (top) and optical microscopic images (bottom) of lunar regolith sample EAC-II. Both dendrite area versus normal glass area structural features can be seen.

\section{Post-processing}

Post-processing of the two batches was different for both cases: the first batch was prepared by manually grinding and polishing the samples, and the second by using a semi-automated process.

\section{Post-processing batch 1}

For the first five samples, the flat bottom side of the samples was ground against a flat glass plate utilising silicon carbide powder of grit sizes 220, 400 and 600 (in that order) to achieve flat and smooth surface. The samples were then polished in two stages using a constantly wetted and spinning felt wheel. In the first step, pumice powder was used and finally a grinding agent called "rouge" which is basically iron oxide
$\left(\mathrm{Fe}_{2} \mathrm{O}_{3}\right)$. The EAC-I and JSC-I samples are depicted in Fig. 3 shown after grinding, polishing and coating. The image furthermore shows the macroscopic surface features in form of bubbles that have formed on the bottom of each sample during heating. This may be due to a supposed interaction of the graphite crucible and/or the ambient air with the basaltic sand.

\section{Post-processing batch 2}

The second set of samples was ground and polished utilising a semi-automated grinding and polishing machine. The machine mounts silicon carbide grinding papers and allows for wet grinding. Samples required holding in place by hand and paper with mean grain sizes from 201 down to $5 \mu \mathrm{m}$ were used successively. The result is depicted in the middle part of Fig. 3. Similar to batch 1, the samples also show macroscopic surface features in the form of bubbles which in two cases are even larger than the bubbles formed on the bottom of the first samples. In particular, the glass manufactured of FJS- 1 shows one major bubble (diameter of $15 \mathrm{~mm}$ ) and the sample made of JSC-2A shows three bubbles in the same size range $(5-10 \mathrm{~mm})$.

\section{Reflective layer deposition}

The reflective layer was deposited on samples of both batches via thermal evaporation. The flat bottom side of batch 1 samples was half-coated in silver and halfcoated with aluminium (top part in Fig. 3), whereas samples of batch 2 (bottom part in Fig. 3) were solely coated with aluminium. The layer thickness of the aluminium deposited onto all samples was more than $600 \mathrm{~nm}$. This is more than the $100 \mathrm{~nm}$ thickness, which is required for maximum reflection of a mirror.

\section{Results}

The surface of the manufactured samples was evaluated with respect to their surface roughness, surface features as well as reflectivity before and after coating the samples with either aluminium or silver. 


\section{Passive microwave heating}

The susceptor-assisted microwave heating approach utilised showed to work by successfully melting all four simulant types. As suggested by [9], a susceptorassisted microwave hybrid heating technique at $2.5 \mathrm{GHz}$ frequency can be used to melt regoliths with different mineral compositions using the same hardware setup. This addition to direct microwave heating greatly increases the flexibility by melting different materials, some of which would not melt using direct microwaving.

Nine different glass-like substrates samples listed in Table 4 were manufactured and did not show any thermal imbalances in the material, in the form of chipping or breaking. Also meaning that all regolith entered into the microwave kiln was melted homogeneously. This is a result of utilising a homogeneous heating pattern created by the susceptor ring in the microwave kiln. Direct microwave heating classically showed inhomogeneous heating behaviour and would lead to thermal stress in the cooled sample.

Differences in geochemical composition of the utilised regolith simulants, as shown in Table 3, may have influenced the susceptor-assisted microwave heating approach. Since differences in iron oxide and magnesium oxide in general influence the behaviour of the melt, it is likely that those have an impact on the properties of the final sample independent of the heating approach used. Different iron oxide contents, for example, will have an impact on the dielectric properties of the regolith (hence the susceptibility to microwaves) or an increased magnesium oxide content which may lead to a higher melting point [14]. Although the silica content doesn't differ significantly for the four different simulants types (43.70-49.14 wt\%), the alumina content does, with a minimum of $12.60 \mathrm{wt} \%$ for EAC-1 and a maximum of $24.40 \mathrm{wt} \%$ for the LHT-3M. A higher aluminium oxide content may well lead to higher melting points and pure alumina (aluminium oxide) is often used in high-temperature furnaces as crucible or lining material. This means in turn that even though the heating approach utilised seemed to heat all different simulants equally well, a combination of cooling and geochemistry of the samples will still influence the characteristics of the final sample. This might be optical characteristics or formation of amorphous and crystalline glasses.
From Table 4 it can further be seen that some of the samples where subject to weight loss during heating. The second batch of samples showed losses as low as almost 0\% (JSC-II sample) up to about 3.2\% for the sample made of EAC-1 (EAC-II). The loss is mostly caused by water evaporating which was contained in the simulant.

\section{Surface features}

Different glasses manufactured from the four simulants listed in Table 3 have been analysed with the scanning electron microscopy (SEM) and optical microscopy. Figure 4 shows an SEM image as well as an optical microscope image of sample EAC-II. Figure 5 shows a SEM image of the polished surface of samples LHT-II, FJS-II and JSC-II.

Looking at the surface of the EAC-II sample, Fig. 4 shows partial recrystallisation of the glass melt in the form of dendrites forming (left on SEM, in the middle of the microscope image). These dendrites form the characteristic tree-like structure with it multibranching off various points. Next to the crystalline zone is a supposedly amorphous glass zone, in both images on the right side of the image.

The glasses made of JSC-2A, FJS-1 and LHT-3Mall also show beginnings of recrystallisation in the glass melt, indicated by the rectangular-shaped crystals seen in the SEM images (Fig. 5). This may have an impact on the reflectivity of the samples when used as mirrors.

Shown in Fig. 6 is an SEM image of the LHT-II sample's surface (top), next to a composite elemental

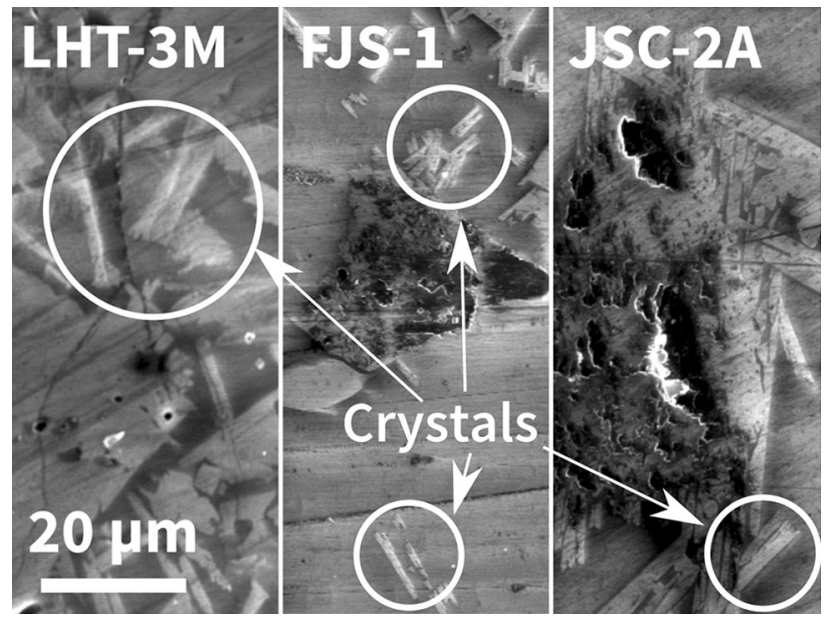

Figure 5 SEM images of the surface of the polished glass samples (left to right) LHT-II, FJS-II, JSC-II. 


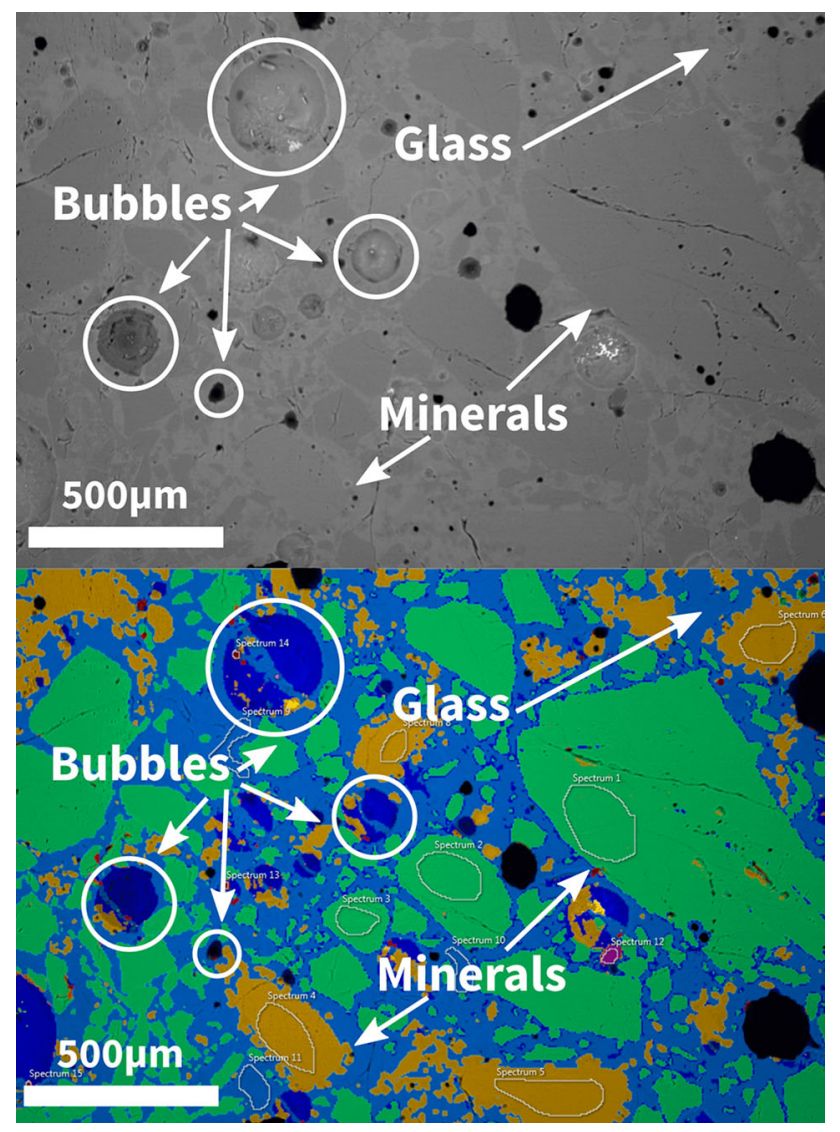

Figure 6 SEM of the LHT-3M glass (top) and EDX maps results in false colour (bottom). The SEM image shows smaller and larger impairments in form of bubbles, un-melted minerals and glass surrounding the minerals. From the EDX image, three major zones can be identified, green blue and orange.

map, from energy-dispersive X-ray (EDX) analysis of the same location (bottom). The image shows that not all minerals have melted during the heating process. These glass zones are indicated by light grey areas in the SEM image in the top part of Fig. 6 and in blue on the EDX false colour image (bottom). In the cold and polished substrate, these non-melted minerals appear to be surrounded by amorphous and partially crystallised glass. Other than the blue zone two other major zones can be identified from the EDX image, a green and an orange zone. Both orange and green are two distinct minerals that have not melted. Their average elemental composition (average of multiple zones of the same colour) is detailed in Table 5. Data indicate that the non-melted minerals should mostly be orthopyroxenes, clinopyroxenes or plagioclases (very anorthite rich). Typically basalts, to a first approximation, can be defined as being a mix of these three, with variable amounts of other minerals such
Table 5 Elemental compositions detected by EDX on the LHT-II sample (Fig. 6)

\begin{tabular}{llll}
\hline Element & Blue $(w t \%)$ & Green $(w t \%)$ & Orange $(w t \%)$ \\
\hline $\mathrm{O}$ & 50.2 & 53.03 & 49.86 \\
$\mathrm{Si}$ & 18.5 & 16.78 & 18.94 \\
$\mathrm{Al}$ & 8.65 & 13.80 & 2.58 \\
$\mathrm{Ca}$ & 6.58 & 9.83 & 1.84 \\
$\mathrm{Mg}$ & 5.48 & - & 13.34 \\
$\mathrm{Fe}$ & 3.7 & 0.48 & 6.2 \\
$\mathrm{Na}$ & - & 0.83 & - \\
Total & 93.11 & 94.75 & 92.76 \\
\hline
\end{tabular}

as olivine and/or amorphous basalt glass. Such a composition is typical for actual lunar samples as well. Table 2 shows the composition of some Apollo mission samples which all contain more than $60 \%$ of plagioclase and pyroxene minerals. A brief overview of the different potential minerals found in the sample:

- Orthopyroxene is formed at high temperatures, hence containing a small amount of calcium as well as aluminium. In this case, however, not enough to call it a pigeonite. Orthopyroxenes are common in basalts especially during partial melting since it crystallises from basaltic glass at high temperatures.

- Clinopyroxene is similar to the above, but with a higher calcium content and also aluminium; hence, it could be classified as augite.

- Plagioclase is less abundant (might be because the grains are less obvious) and analyses suggest that it is anorthite-rich, which is to be expected at temperatures as high as the used processing temperature.

It is likely that the green areas-in the EDX image (Fig. 6, bottom)—are calcium rich (9.83\%) plagioclase feldspars, which should be labradorite and bytownite since both are rich in anorthite. The orange areas appear to be pyroxenes ( $13.34 \%$ magnesium, low aluminium $(2.58 \%)$ and calcium $(1.84 \%)$ ) as, for example, the clinopyroxene augite, which is a common mineral in basalt. The exact reason why those minerals did not melt in LTH-3M is not obvious, but may be that the lower total iron oxide $\left(\mathrm{FeO}+\mathrm{Fe}_{2} \mathrm{O}_{3}\right)$ content of $4.16 \%$, itself could be the reason. With $10.75 \mathrm{wt} \%$ (JSC-2A), $12.00 \mathrm{wt} \%$ (EAC-1) and 
$13.07 \mathrm{wt} \%$ (FJS-1) of total iron oxide content, the other three simulants show significantly higher values.

Since the iron oxide is the oxide which is most susceptible to microwaves (due to coupled dielectric heating mode $[4,7,9,63])$, and hence microwave heating, an increase in iron oxide content might improve heating in a microwave kiln. Since the LHT$3 \mathrm{M}$ is iron sparse, this additional means of heating the regolith is reduced to a minimum and suggests that the susceptor-assisted microwave heating approach is not performing equally for all input materials. The other possibility is that those particular minerals or the combination of those minerals lead to a higher melting point of the LHT-3M in general. Hence, the microwave heating process achieves its maximum possible temperature with the current setup but is still not capable of heating the sample beyond melting temperature.

Another interesting point about the LHT-3M glass (Fig. 3) is that it appear distinct green compared to all other glass types. One possibility for the green colour of the glass is the occurrence of traces of chromium, contained in diopside or chrome spinels which would turn a glass melt green. A second possibility would be if the sample contains traces of nickel, within olivines, which would also lead to a green colouring.

\section{Surface topography}

The surface features and structures have been measured and characterised by means of profilometery and focus variation microscopy. Surface profiles and surface feature size could be determined. Surface topography images of the regolith samples (Fig. 7) were taken using the technique of focus variation microscopy (Alicona InfiniteFocus, Austria)-a nondestructive way to create a three-dimensional surface profile were created using the technique of focus variation microscopy (Alicona InfiniteFocus, Austria). The technique provides a measurement of areal surface topography based on optics with limited depths of field and vertical scanning [64-66].

Figure 7(top) shows a top view of the reconstructed three-dimensional surface profile of the EAC-II sample. It also shows the extraction of the surface profile at three different sites of the sample's surface along a horizontal profile path. The results of these surface profiles are depicted in the bottom half of Fig. 7. Graph (a) shows the surface profile of an area with almost no cavities. Maximum deviations observed from the zero plane are in the range of 400 to $-800 \mathrm{~nm}$, with a maximum $\Delta$ of $1200 \mathrm{~nm}$. Looking at the two other plots ((b), (c)) two larger surface features (formed by bubbles) can be seen: one (b) in the range of $5 \mu \mathrm{m}$ in depth and the other of about $40 \mu \mathrm{m}$.

In addition to the SEM image (Fig. 4, top) and the optical microscopic image (Fig. 4, bottom), the 3D reconstructed image (Fig. 7) shows the surface of the same sample. As pointed out in section "Surface features" already, also this measurement shows a transition between non-crystalline and crystalline structural features, indicated by the branching structure of dendrites that have formed and are visible in brighter green.

\section{Surface roughness}

A Taylor Hobson Talysurf-5 modular system was used to characterise and quantify the surface texture profiles of the basaltic glass samples from both batches. The modular system has a sensitivity tolerance standard linearity of $\pm 2.0 \%$, and the linear recorder of the system records on electro-sensitive chart paper, driven by a synchronous motor. The recorded plots were individually scanned at $600 \mathrm{dpi}$, and XY coordinates of each measured point were exported. Furthermore, drifts in vertical axis due to sample mounting have been accounted for and corrected. Each sample of the nine samples of both batches, as well as a microscopy slide (sample name MS-001), was placed on the stand parallel to the line of pick-up travel directly under the stylus. The instrument was always set up to make one trace across the surface (as depicted in Fig. 3) with the vertical magnification, $V_{\mathrm{v}}$, set to $x 200$ or $x 500$, subject to a visual inspection of the samples surface quality. The horizontal magnification, $V_{\mathrm{h}}$, was set to $\mathrm{x} 5$ for all samples measured other than the reference microscopy slide (MS-001) which has been measured using $\times 20$. This was done to ensure that the horizontal length allowed was sufficient to obtain the profile record of each sample.

Table 6 provides an overview of the surface features of the glass samples. These values were calculated based on the measurements recorded with the modular system (results displayed in Fig. 8). The average mean vertical height is determined to form a base line height for each sample, with the average mean vertical values above and below this base line 

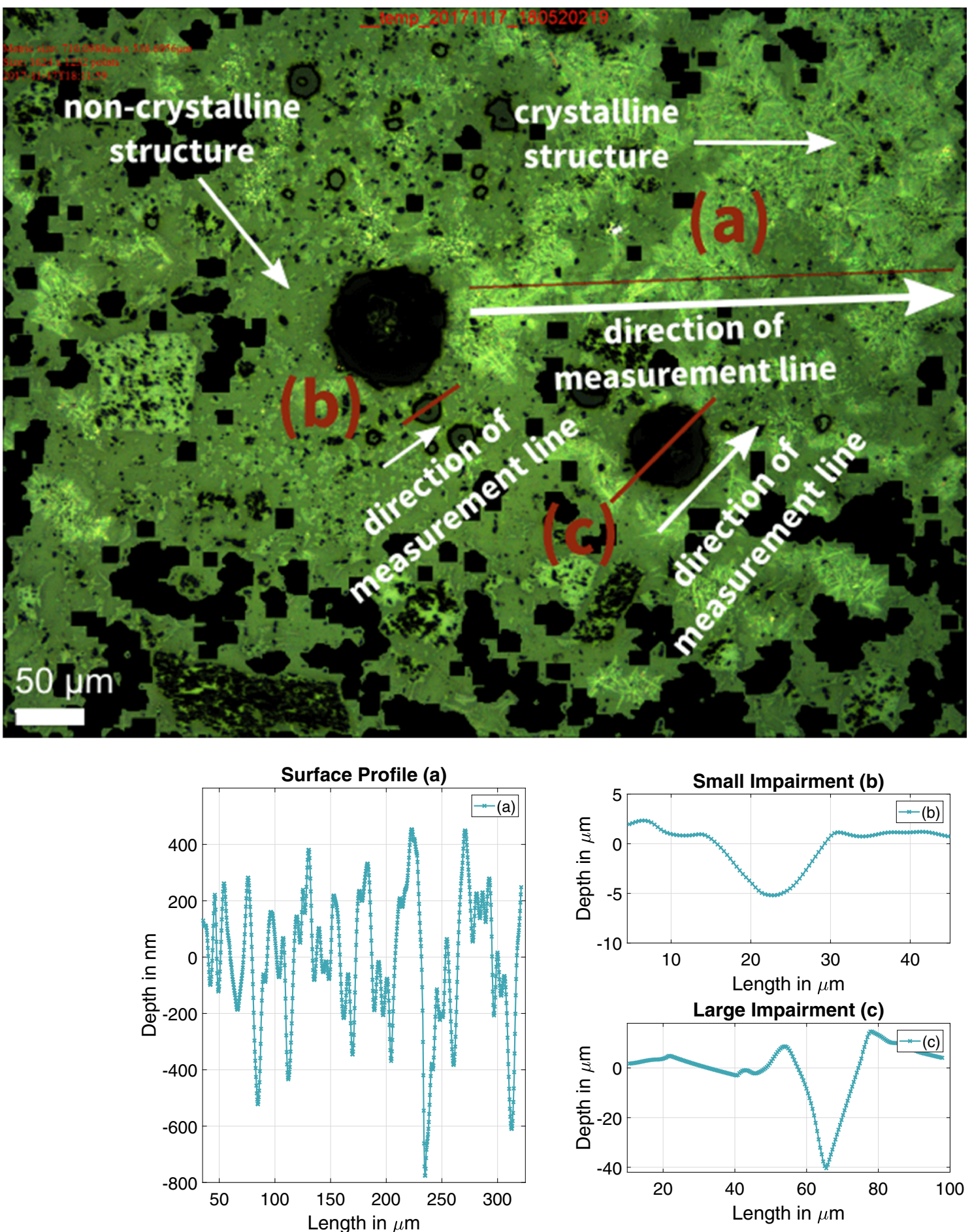

Figure 7 Surface topography image, measured by surface variation microscopy (see text for further details). Showing the surface of the sample EAC-II, green-coloured areas indicate recorded data points (black areas missing data). At three different sites of the sample, measurements have been extracted where the red line denotes the actual site of the line of measurement and the white line its direction. Both non-crystalline (darker green) and crystalline (light green) structural features can be seen. The measurement direction corresponds to the x-axis in the plots. Subplots in the bottom part show: a plane surface, $\mathbf{b}$ small impairment and $\mathrm{c}$ large impairment. 
Table 6 Overview of surface roughness data

\begin{tabular}{lcrrcrc}
\hline Sample ID & $V_{\mathrm{v}}(\mu \mathrm{m})$ & $h_{\mathrm{v}}(\mu \mathrm{m})$ & \multicolumn{1}{c}{$h_{\text {top }}(\mu \mathrm{m})$} & $h_{\text {below }}(\mu \mathrm{m})$ & $\delta_{\mathrm{h}}(\mu \mathrm{m})$ & $\zeta(\mu \mathrm{m})$ \\
\hline Batch 1 & & & & & & \\
EAC-I-1 & 500 & -3.09 & 11.26 & -23.43 & 34.69 & 20.05 \\
EAC-I-2 & 500 & -13.17 & 0.06 & -36.21 & 36.26 & 20.43 \\
EAC-I-3 & 500 & -7.10 & 4.49 & -23.14 & 27.63 & 16.31 \\
JSC-I-1 & 200 & 9.81 & 29.48 & -24.55 & 54.03 & 33.32 \\
JSC-I-2 & 200 & -45.89 & 3.62 & -128.25 & 131.87 & $74.87(19.41)$ \\
Batch 2 & & & & & & \\
EAC-II & 200 & 11.35 & 20.51 & -11.75 & 32.27 & 19.88 \\
LHT-II & 200 & -10.57 & 8.30 & -51.90 & 60.20 & 38.71 \\
FJS-II & 200 & 7.22 & 14.72 & -8.93 & 23.65 & 13.30 \\
JSC-II & 200 & -1.42 & 5.25 & -15.85 & 21.10 & 11.88 \\
Reference sample & & & & & \\
Microscopy & & & & & & \\
Slide & 500 & 0.44 & 5.15 & -2.13 & 7.28 & 0.25 \\
\hline V & & & &
\end{tabular}

$V_{\mathrm{v}}$, vertical magnification; $h_{\mathrm{v}}$, average mean vertical height; $h_{\text {top }}$, mean values above average, $h_{\text {below }}$, mean values below average; $\delta_{\mathrm{h}}$, mean delta high-low values; $\zeta$, deviation values in brackets are refined
Figure 8 Surface roughness of the first batch of EAC-I and JSC-I samples (top) and the second batch of JSC-II, LHTII, EAC-II, FJS-II samples (bottom).
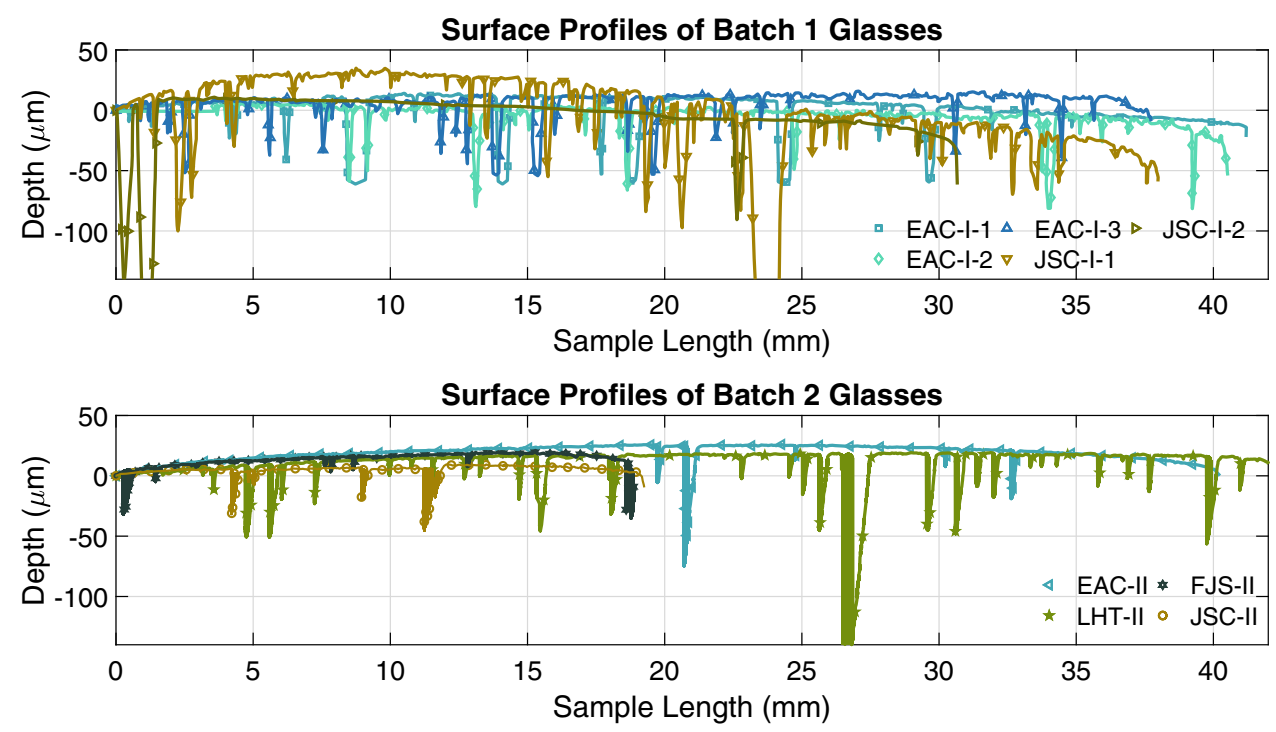

calculated to provide a typical mean delta high-low value representative of the samples typical surface roughness range.

Shown in Table 6 is the deviation in the direction of the normal vector, $\zeta$, of each sample, which has been derived to provide quantitative values for surface roughness. The distance the stylus was dragged along the surface was in-between 37 and $42 \mathrm{~mm}$ for JSC-I and EAC-I samples other than JSC-I-2 which could only be measured for about $30 \mathrm{~mm}$ due to its shape. Batch 2 samples EAC-II and LHT-II were measured for $40-42 \mathrm{~mm}$ and JSC-II and FJS-II for only $18 \mathrm{~mm}$ because of their major voids. The direction is indicated by the red arrow in Fig. 3.
The microscopy slide was used as reference and measured to have a deviation of $\zeta=0.25 \mu \mathrm{m}$ over a surface path of $70 \mathrm{~mm}$. Relative to the basaltic glass samples, the microscopy slide is considered to have a smooth surface texture. The basaltic glass samples have considerably greater deviations than the microscopy slide, within the maximum case $74.62 \mu \mathrm{m}$ difference to the microscopy slide. Samples JSC-II and FJS-II show the smallest total deviations with less than $15 \mu \mathrm{m}$. These samples might be better based on their low porosity or small number of bubbles formed during manufacturing (section "Heating and shaping") which might have lead to the differences in surface quality. Since all nine samples have been 
treated with the same grinding process and grinding powders/papers, it is unlikely that differences in surface finish relate to the grinding process but are rather due to the materials composition and texture. Additionally, an average deviation of $\zeta=33.00 \mu \mathrm{m}$ could be calculated for all batch 1 samples and $\zeta=20.94 \mu \mathrm{m}$ for all batch 2 samples. This suggests a better average surface quality for batch 2 samples than batch 1 samples which in return might suggest that the changes in manufacturing and processing time might impact the final surface finish, such as the switch over from manual to semi-automated grinding.

\section{Surface roughness batch 1}

Depicted in Fig. 8 are the data of the surface roughness measurements, recorded by the Taylor Hobson Talysurf-5. Numerical results are summarised in Table 6, and the graphs show surface features across the surface (measured as indicated in Fig. 3).

The two curves of samples JSC-I-1 and JSC-I-2 shown in the graph are different from each other in terms of their surface profile. Although sample 02 optically appears to be smoother than 01 , values from Table 6 show that their deviation values are $33.32 \mu \mathrm{m}$ (JSC-I-1) and $74.87 \mu \mathrm{m}$ (JSC-I-1) and hence it seems the opposite way. Considering that the initial $1.5 \mathrm{~mm}$ of the measurement path of sample JSC-I-2 contains multiple surface features deeper than $250 \mu \mathrm{m}$, it may seem more interesting to compare only the part of the JSC-I-2 sample which is smoother. Correcting for the voids by discarding the first $1.5 \mathrm{~mm}$ of measurements at the beginning of the path, the deviation of sample reduces to $19.41 \mu \mathrm{m}$. This value is now in line with the optical observation and suggests that the bulk part of the surface of the JSC-I-2 sample is indeed smoother than the surface of JSC-I-1.

The voids at the edge of sample JSC-I-2 were most likely formed during the casting, where bubbles might have been trapped in the first bit of the melt hitting the mould. For the rest of the sample it is, however, also likely that because of the casting process bubbles, contained in the melt, could escape to the sides, leading to increased surface smoothness. The depth of the majority of bubbles formed in both JSC-I samples is in the range of $40-60 \mu \mathrm{m}$, with larger bubbles being as deep as several millimetres.

All surface profiles of the three EAC-I samples show similar surface profiles as well as number and size of voids. The EAC-I samples show bubbles in the range of $40-60 \mu \mathrm{m}$ but no larger bubbles $(>1 \mathrm{~mm}$ ) that could be detected on the JSC-I samples. Smaller bubbles found all over the EAC-I samples are in the range of $1-5 \mu \mathrm{m}$ and are indicated by small peaks in the curves in Fig. 8. Generally, the data displayed in that figure show that EAC-I samples are smoother (less surface features) than the JSC-I samples.

\section{Surface roughness batch 2}

The surface roughness of batch 2 samples was recorded in the same fashion as it was recorded for the first batch, along the longest axis of the sample. Result is depicted in the bottom graph in Fig. 8. Due to macroscopic surface features $(>250 \mu \mathrm{m})$, two out of the four samples could only be measured for about half $(18 \mathrm{~mm})$ the distance than the two others $(42 \mathrm{~mm})$. Other than the different length of measurement paths, the procedure was identical for all four samples.

The surface roughness of the second batch (Fig. 8, bottom, and Table 6) was, on average, smoother than the first batch with an overall average deviation of $24.23 \mu \mathrm{m}$ (nominally, a reduction of $8.77 \mu \mathrm{m}$ compared to batch 1, but had similarly sized (and partially greater) microscopic bubbles than the first batch. The general shape and hence the surface profile of the samples seemed to be rather similar in depth and number of voids. It appears that the LHTII sample appears to have the highest number of surface features and the sample JSC-II the fewest. This is also reflected in the deviation $\zeta$ values in Table 6 where sample LHT-II (LHT-3M) shows a deviation of $\zeta=38.71 \mu \mathrm{m}$ and sample JSC-II $\zeta=11.88 \mu \mathrm{m}$.

Moreover, the surface of the LHT-3M substrate glass seems to have a larger number of small scale $(<500 \mu \mathrm{m})$ bubbles than the other samples. This might have been caused due to the (compared to the other samples) extended heating time which also increased the time for interaction with the graphite crucible. The bubbles could have also been out-gassing from the regolith simulant itself which could not escape the melt since its viscosity was possibly too high for them to penetrate to the surface. 
Comparison of surface roughness and topography

Comparing results from the focus variation microscopy (Fig. 7) and data of the profilometer (Fig. 8), the areas in-between the larger cavities, observed in both measurements, seem to match in behaviour and surface feature size. From sub-plot (a) in Fig. 7 the maximum deviations from the zero line, for the measurement across a part of the surface with no larger voids, are about $+400 \mathrm{~nm}$ and $-800 \mathrm{~nm}$. This is consistent with the parts of the profilometer curves which lie in-between the larger voids and appear to be rather smooth meaning variations in depth of less than 2-3 $\mu \mathrm{m}$ would not show up as peaks. Moreover, the two voids measured and shown in sub-plots (b) and (c) in Fig. 7 show depths of about -5 to $-40 \mu \mathrm{m}$. Graphs of the profilometer (Fig. 8, bottom) show, in most but three cases, void depths of in-between -5 and $-50 \mu \mathrm{m}$; hence, both observations are consistent.

\section{Flatness}

From the surface texture data displayed in Fig. 8 (profilometer data), the flatness of the samples can be estimated. Therefore, the largest difference in height $(\Delta h)$ was found to be $\Delta h_{\mathrm{JSC}-\mathrm{I}-1}=85 \mu \mathrm{m}$ for sample JSC-I-1 and $\Delta h_{\mathrm{EAC}-\mathrm{II}}=25 \mu \mathrm{m}$ for batch EAC-II. Smallest height differences in batch 1 are $\Delta h_{\mathrm{EAC}-\mathrm{I}-3}=$ $15 \mu \mathrm{m}$ for sample EAC-I-3 and $\Delta h_{\mathrm{JSC}-\mathrm{II}}=12 \mu \mathrm{m}$ for sample JSC-II. It may be pointed out again that the measurement path of JSC-II was only $18 \mathrm{~mm}$ and therefore about $50 \%$ shorter than most other samples. These values describe the distance between maximum and minimum height of the entire measured length of the sample. This is not considering any microscopic voids but rather the entire surface profile itself as it would be without voids.

In all cases, for all nine samples, it appears that the surface of the samples is convex. This can be explained due to the grinding and polishing process which takes off more material at the edges of a samples than it does in its middle. Although a convex shape is not desirable for building a reflector, the diverging effects of these substrates (with a convex shape) are not considered to be relevant for the measurements displayed next. Since the light propagation paths are only $20-100 \mathrm{~cm}$, the losses will be minor for such slight convex shapes.

\section{Reflectivity}

Achieving a high reflectivity for a coated basalt glass mirror is key to maximising energy that can be harvested or diverted by it. Used in a solar concentrator system or a solar furnace increased amount of reflected light will lead to higher efficiencies of the overall system. Hence, it is of interest to understand which parameters influence the performance of such a mirror and how to maximise its performance. Therefore, the reflectivity of three different surface types has been measured: uncoated, aluminiumcoated and silver-coated basaltic glasses. All reflectivity data gathered were recorded on a PerkinElmer Lambda 950 UV-Vis-NIR spectrometer. This machine has its detector handover at $860.8 \mathrm{~nm}$ and light bulb change from the deuterium lamp to the tungsten lamp happens at $319.2 \mathrm{~nm}$. Therefore, measurements of the reflectivity close to these wavelengths show discontinuations in the measurements.

\section{Uncoated samples}

Before coating the samples, it is of interest to know about the uncoated samples' ability to reflect light. For both batches the amount of reflected light lies inbetween approximately 4-13\% (Fig. 9), in the wavelength range from 300 to $1250 \mathrm{~nm}$.

The only exception is the sample made of LHT-3M, which is significantly more reflective for wavelengths around $300-900 \mathrm{~nm}$ (peak of $28 \%$ at approximately $540 \mathrm{~nm}$ ). This corresponded to its apparent green colour, with green light been part of the visible spectrum and ranging from 490 to $570 \mathrm{~nm}$. Peak reflectivity is observed in this approximate range.

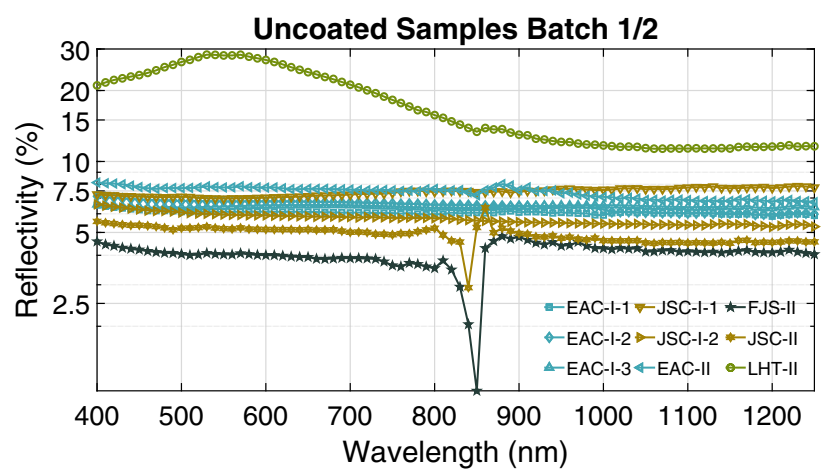

Figure 9 Reflectivity of glass raw samples before coating - batch 1 shown in solid lines, batch 2 in dotted lines. 
The EAC-II sample has consistently higher average reflectivities compared to the FJS-II and JSC-II samples. This could be explained due to the core of the EAC-II sample being grey in appearance rather than black. These grey areas correspond to the areas where most of the glass has crystallised. This would suggest that crystallisation of the glass is indeed favourable for the reflective behaviour of the raw glass.

Considering the deviation ( $\zeta$ ) from Table 6 , batch 1 samples listed in the order from roughest to smoothest are: JSC-I-2, JSC-I-1, EAC-I-2, EAC-I-1 and EAC-I-3 and for batch 2: LHT-II, EAC-II, FJS-II and JSC-II. This order is, however, not reflected in the measurements depicted in graph 9 where JSC-I-1 performs best, just before EAC-I-3/2 for batch 1 . For batch 2, the LHT-II sample outperforms all other samples by more than double, to almost quadrupole for some wavelengths, with second best (of batch 2) being the EAC-II, which is second worst for the deviation/roughness. This is counterintuitive and suggests that surface finish may not be the main metric impacting the reflectivity of the uncoated basaltic glasses. Hence, geochemistry and mineralogy likely have a dominant impact on the reflective properties of the samples.

Since the quality of the glass samples' surfaces could not clearly be connected to their reflectivity values, Fig. 10 shows reflectivity (averaged for samples of same simulant) versus their iron oxide content ( $\mathrm{FeO}$ and $\mathrm{Fe}_{2} \mathrm{O}_{3}$ combined). Looking at the trend of the fitted curve, it seems that the iron oxide content may be directly related to the samples ability to reflect. It suggests that iron sparse regoliths such as LHT-3 $\mathrm{M}$ have better reflectivity than iron rich regoliths as in this case FJS-1.

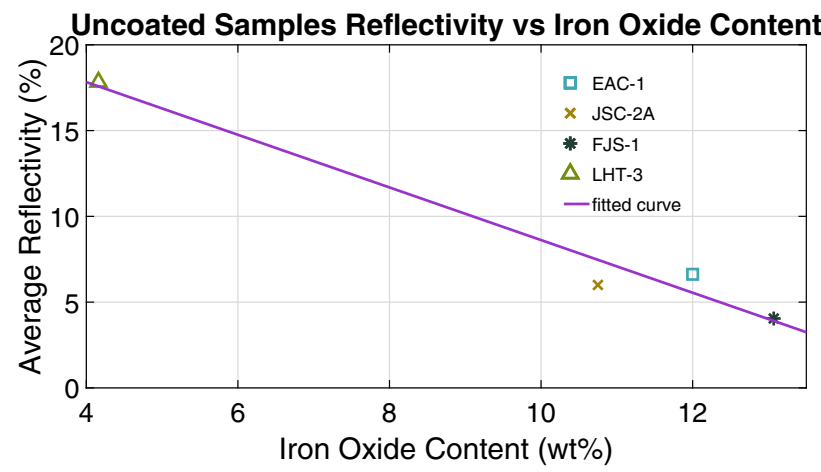

Figure 10 Average reflectivity of uncoated EAC-1, LHT-3M, JSC-2A and FJS-1 samples versus iron oxide content ( $\mathrm{FeO}$ and $\mathrm{Fe}_{2} \mathrm{O}_{3}$ combined).

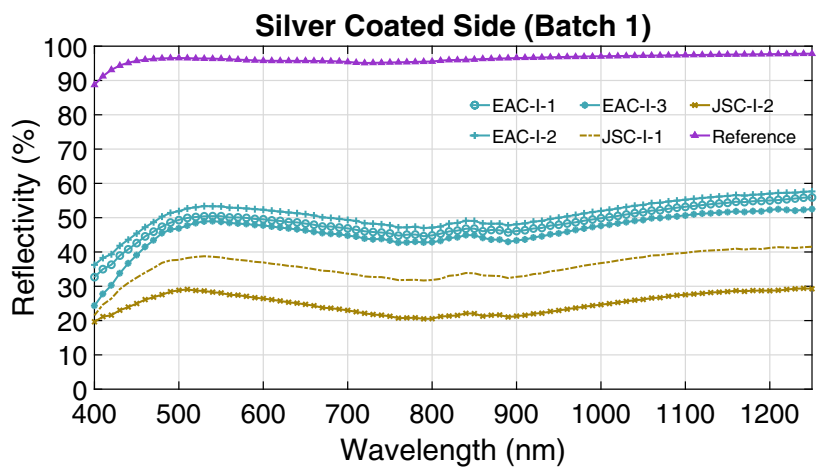

Figure 11 Reflectivity of silver-coated side-batch 1, indicated in violet with triangle markers a reference mirror from THOR labs that has been coated with silver plus a protective layer.

\section{Silver-coated samples}

The reflective behaviour of the silver-coated part of the batch 1 samples is depicted in Fig. 11. With reflectance levels in-between 20 and $60 \%$, the silver coating drastically increased the amount of reflected light compared to their values when uncoated, shown in Fig. 9.

Compared to the reference mirror ("Protected $\mathrm{Ag}^{\prime}$ ), the samples still perform only at one half to onefourth of the reference mirror. This may be the case due to the poor surface quality compared to the reference microscopy slide listed in Table 6. Another reason could be that the silver coating might have already started to oxidise in air.

\section{Aluminium-coated samples}

The second coating material chosen for both batches was aluminium. This choice was made due to aluminium having the best average reflectance (compared to all materials analysed [67] for this work), over a wide wavelength spectrum. Moreover, it is comparably light and cheap and therefore seems a favourable choice as coating material for mirrors on the lunar surface, where weight is an important factor. The reflectivity of all samples was measured on the PerkinElmer spectrometer, and the results are depicted in Fig. 12. All nine samples are shown plus reference data from an aluminium-coated mirror (with protection layer) provided by commercial supplier. It can be seen that the performance of all batch 1 samples (aluminium-coated side) is slightly higher than the performance of the silver-coated side. Moreover, the JSC-II sample performed best, as it 


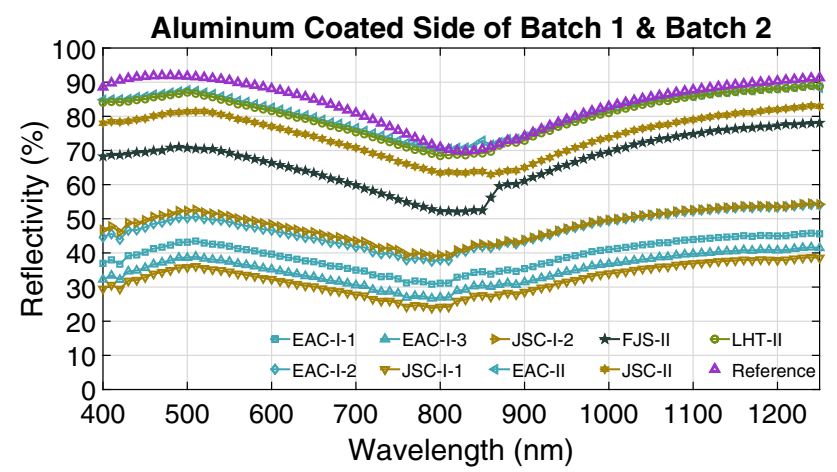

Figure 12 Reflectivity of aluminium-coated side - batch 1 (full lines), batch 2 (dashed lines) and reference mirror (triangles).

would have been expected due to its smoothest surface. It may be added that the silver-coated samples performed slightly better in the infrared wavelength ranges, which was expected from the relevant literature [67].

Both batches were partially (batch 1) or entirely (batch 2) coated with aluminium (Fig. 3). Batch 1 samples show on average a reflectivity of $25-50 \%$ for most parts of the measured wavelength spectrum. Batch 2 samples exceed expectations with reflectivity values almost as high as $90 \%$ for some parts and for most parts in-between 50 and $85 \%$. The worst batch 2 sample was the sample FJS-II with about $65 \%$ average reflectivity, the best the EAC-II and LHT-II samples with about $80 \%$.

For the aluminium-coated samples, the trend of all curves seems to be similar to the trend of the aluminium-coated reference mirror (indicated in violet in Fig. 12). This looks similar to the behaviour of the silver-coated samples and makes it seem possible to produce mirrors of a quality good enough to be used in a solar reflector system.

When comparing surface roughness (section "Surface topography"), in both batches, it is apparent that higher reflectivity is obtained for samples considered to have low deviations ( $\zeta)$. A plot showing reflectivity over surface roughness of all batches and both aluminium and silver is shown in Fig. 13. This is to be expected and true for all samples but the silvercoated side of JSC-I-2 which may be different because of macroscopic surface features. It can be seen that the performance of all batch 1 samples (aluminiumcoated side) is slightly higher than the performance of the silver-coated side. This supports the theory that aluminium is the more suitable coating material since it might be more tolerable to low-quality substrates.

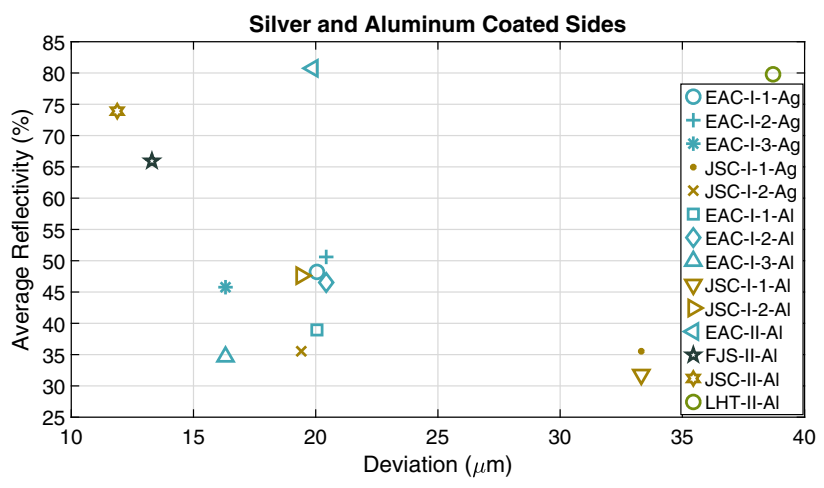

Figure 13 Reflectivity of aluminium- and silver-coated sides of both batches versus surface roughness.

Moreover, the EAC-II and LHT-II sample performed best, although their surface does not appear to be the smoothest of all samples. Looking back at the surface profiles of those samples, they have a high deviation level because they contain many voids but the surface area in-between those voids is rather smooth.

With a decrease in surface quality, the amount of reflected light is also decreasing (Fig. 13). In some cases, with a rather high deviation, it is still possible to achieve a reasonable reflectivity. This finding supports the idea of utilising regolith to manufacture mirrors on the lunar surface utilising uncomplicated technology seems feasible.

\section{Conclusion}

Samples from four different lunar regolith types could successfully be melted in a susceptor-assisted microwave heating approach, utilising a microwave kiln. After cooling and annealing, mostly amorphous glasses were formed that showed smaller crystallised areas. All samples could be turned into approximately $20 \times 45 \mathrm{~mm}$ size glass or glass-like samples, which were ground and polished. Two different independent batches were manufactured and polished and then measured for their reflective properties. Results indicate that reflective properties of uncoated but polished samples, for all but one sample, are as low as $5-10 \%$ in-between a wavelength range of $400-1250 \mathrm{~nm}$. The exception is glass manufactured of LHT-3M simulant, which has a peak of $28 \%$ in the green wavelength spectrum which seemed to be related to the iron oxide content of the raw regolith. For all samples the reflectivity could be increased by a factor of $5-10$ by coating the surface 
with silver or aluminium. Reflective peaks of about $90 \%$ could be reached in the near-infrared spectrum, which is only a few per cent off the performance of an aluminium-coated reference mirror.

In conclusion, it can be said that melting lunar regolith turning it into glass substrates and coating it with a reflective material for the production of usable mirrors is feasible. Moreover, we feel that these experiments show that the process could produce similar results of the lunar surface. Additionally, the susceptor-assisted microwave heating process used in this work seems to be mostly independent of the input material and may be an option for an energyefficient and universal heating method which could be deployed on the lunar surface.

Next steps to take this technology further should include improvements to substrates surface quality, up-scaling and testing under lunar-like conditions. In particular, future tests should aim at reducing the formation of bubbles during the melting process, to ultimately increase the surface quality. This may be achieved by improvements to the preparation of the raw regolith, use of different crucible materials, heating methods or grain size distributions. A study on the impact of different mineral compositions on melting points will be necessary to assess the susceptor-assisted microwave heating process further and to assure that it is as universal as required.

\section{Acknowledgements}

The authors would like to thank Dr. Uwe Wolfram at Heriot-Watt University and his team for the support on the surface profiling, as well as Dr. Geoffrey Bromiley at Edinburgh University for the support on the geological analysis of the samples.

\section{Funding}

This research was co-funded under the ESA NPI scheme.

\section{Compliance with ethical standards}

Conflict of interest The authors declare that they have no conflict of interest.

Open Access This article is distributed under the terms of the Creative Commons Attribution 4.0
International License (http://creativecommons.org/ licenses/by/4.0/), which permits unrestricted use, distribution, and reproduction in any medium, provided you give appropriate credit to the original author(s) and the source, provide a link to the Creative Commons license, and indicate if changes were made.

\section{References}

[1] Shafto M, Conroy M, Doyle R, Glaessgen E, Kemp C, LeMoigne J, Wang L (2012) Draft modeling, simulation, information technology and processing roadmap. National Aeronautics and Space Administration (NASA), Technology Area, vol 11. Washington, DC, USA

[2] Hufenbach B, Reiter T, Sourgens E (2014) Esa strategic planning for space exploration. Space Policy 30(3):174-177

[3] Sanders G, Larson W, Sacksteder K, Mclemore C (2008) Nasa in situ resource utilization (ISRU) project: development and implementation. In: AIAA SPACE 2008 conference and exposition, p 7853

[4] Taylor LA, Meek TT (2005) Microwave sintering of lunar soil: properties, theory, and practice. J Aerosp Eng 18(3):188-196

[5] Allan S, Braunstein J, Baranova I, Vandervoort N, Fall M, Shulman H (2012) Computational modeling and experimental microwave processing of JSC-1a lunar simulant. J Aerosp Eng 26(1):143-151

[6] Barmatz M, Steinfeld D, Anderson M, Winterhalter D (2014) $3 \mathrm{~d}$ microwave print head approach for processing lunar and mars regolith. In: Lunar and planetary science conference, vol 45, p 1137

[7] Cowley A, Haefner T, Beltzung J, Meurisse A (2015) Spaceship EAC-fostering activities relevant to lunar exploration and ISRU. LPI Contrib 1863:2037

[8] Znamenáčková I, Dolinská S, Kováčová M, Lovás M, Čablík V, Čablíková L (2015) Innovative method of material treatment by microwave energy. Proc Earth Planet Sci $15: 855-860$

[9] Srivastava V, Lim S, Anand M (2016) Microwave processing of lunar soil for supporting longer-term surface exploration on the moon. Space Policy 37:92-96

[10] Heiken G, McKay DS (1974) Petrography of apollo 17 soils. Lunar Planet Sci Conf Proc 5:843-860

[11] Papike J, Simon S, Laul J (1982) The lunar regolith: chemistry, mineralogy, and petrology. Rev Geophys 20(4):761-826

[12] Heiken G, Vaniman D, French BM (1991) Lunar sourcebook: a user's guide to the Moon. CUP archive, chapter 7 
[13] Lindsay JF (1976) Lunar stratigraphy and sedimentology. Elsevier Scientific Publishing Co., Amsterdam (Developments in solar system-and space science, no. 3), vol 1, pp 227-287

[14] Roeder P, Emslie R (1970) Olivine-liquid equilibrium. Contrib Miner Petrol 29(4):275-289

[15] Jaumann R, Hiesinger H, Anand M, Crawford IA, Wagner R, Sohl F, Jolliff B, Scholten F, Knapmeyer M, Hoffmann H et al (2012) Geology, geochemistry, and geophysics of the moon: status of current understanding. Planet Space Sci 74(1):15-41

[16] Ulrich GE, Hodges CA, Muehlberger WR (1981) Geology of the apollo 16 area, central lunar highlands. Technical report, USGPO: For sale by the Supt. of Docs

[17] Dhingra D, Head JW, Pieters CM (2016) Geological mapping of impact melt deposits at lunar complex craters Jackson and Tycho: morphologic and topographic diversity and relation to the cratering process. Icarus

[18] Lognonné P, Gagnepain-Beyneix J, Chenet H (2003) A new seismic model of the moon: implications for structure, thermal evolution and formation of the moon. Earth Planet Sci Lett 211(1):27-44

[19] Heiken G, Vaniman D, French BM (1991) Lunar sourcebook: a user's guide to the Moon. CUP Archive

[20] Meyer C (2003) Lunar sample mineralogy. NASA lunar petrographic educational thin section set, pp 8-9

[21] Chemin YH, Crawford IA, Grindrod P, Alexander L (2016) Assessment of spectral properties of apollo 12 landing site. PeerJ Preprints 4: e2124v1

[22] McLeod CL, Brandon AD, Fernandes VA, Peslier AH, Fritz J, Lapen T, Shafer JT, Butcher AR, Irving AJ (2016) Constraints on formation and evolution of the lunar crust from feldspathic granulitic breccias NWA 3163 and 4881. Geochim Cosmochim Acta 187:350-374

[23] Longhi J (2006) Petrogenesis of picritic mare magmas: constraints on the extent of early lunar differentiation. Geochim Cosmochim Acta 70(24):5919-5934

[24] Longhi J, Durand SR, Walker D (2010) The pattern of ni and co abundances in lunar olivines. Geochim Cosmochim Acta 74(2):784-798

[25] McLemore C (2009) The need for lunar simulants. In: LPI contributions, vol 1515, p 40

[26] Carter JL, McKay DS, Taylor LA, Carrier III WD (2004) Lunar simulants: Jsc-1 is gone; the need for new standardized root simulants

[27] Sibille L (2013) Lunar simulants, analogues, and standards: needs and realities for mission technologies development

[28] Taylor LA, Pieters CM, Britt D (2016) Evaluations of lunar regolith simulants. Planet Space Sci 126:1-7
[29] Stoeser D, Rickman D, Wilson S (2010) Design and specifications for the highland regolith prototype simulants nu-lht$1 \mathrm{~m}$ and $-2 \mathrm{~m}$

[30] Sibille L, Carpenter P, Schlagheck R, French RA (2006) Lunar regolith simulant materials: recommendations for standardization, production, and usage

[31] Weinstein M, Wilson SA (2013) Apparatus and method for producing a lunar agglutinate simulant, December 17, 2013. US Patent 8,610,024

[32] Mackenzie J, Claridge R (1979) Glass and ceramics from lunar materials. In: 4th conference on space manufacturing facilities. Princeton University, p 1381

[33] Vaniman D, Meek T, Blake R (1986) Fusing lunar materials with microwave energy. Part ii: Melting of a simulated glassy apollo 11 soil. Lunar Planet Sci Conf 17:911-912

[34] T. E. of Encyclopedia Britannica (2018) Definition obsidian

[35] Delano JW (1986) Pristine lunar glasses: criteria, data, and implications. J Geophys Res Solid Earth 91(B4):201-213

[36] Saunders AD, Tarney J (1984) Geochemical characteristics of basaltic volcanism within back-arc basins. Geol Soc Lond Spec Publ 16(1):59-76

[37] Frey F, Walker N, Stakes D, Hart S, Nielsen R (1993) Geochemical characteristics of basaltic glasses from the AMAR and FAMOUS axial valleys, mid-Atlantic Ridge $\left(36^{\circ}-37^{\circ} \mathrm{N}\right)$ : petrogenetic implications. Earth Planet Sci Lett 115(1-4):117-136

[38] Yilmaz S, Özkan OT, Günay V (1996) Crystallization kinetics of basalt glass. Ceram Int 22(6):477-481

[39] Tarrago M, Royo I, Garcia-Valles M, Martínez S (2016) Nucleation and crystallization of $\mathrm{Ca}$ doped basaltic glass for the production of a glass-ceramic material. In: EGU general assembly conference abstracts, vol 18, p 15165

[40] Khater GA, Safiah MOA, Hamzawy EM (2015) Augiteanorthite glass-ceramics from residues of basalt quarry and ceramic wastes. Process Appl Ceram 9(2):117-123

[41] Cetin S, Marangoni M, Bernardo E (2015) Lightweight glass-ceramic tiles from the sintering of mining tailings. Ceram Int 41(4):5294-5300

[42] Hassaan M, Saudi H, Saad HM, Mostafa A, Ahmed M, Iida Y, Kubuki S, Nishida T (2015) Structural study of glass and glass ceramics prepared with Egyptian basalt. Silicon 7(4):383-391

[43] Hartlieb P, Toifl M, Kuchar F, Meisels R, Antretter T (2016) Thermo-physical properties of selected hard rocks and their relation to microwave-assisted comminution. Miner Eng 91:34-41

[44] Alexander J, Augustine B (2015) The effect of combined thermal and microwave curing on mechanical properties and surface hardness of basalt/epoxy composites. Middle-East J Sci Res 23(2):347-349 
[45] Nekoovaght P, Gharib N, Hassani F et al (2015) The behavior of rocks when exposed to microwave radiation. In: 13th ISRM international congress of rock mechanics. International Society for Rock Mechanics

[46] Li W, Wei J, Wang W, Hu D, Li Y, Guan J (2016) Ferritebased metamaterial microwave absorber with absorption frequency magnetically tunable in a wide range. Mater Des 110:27-34

[47] Batchelor A, Jones D, Plint S, Kingman S (2015) Deriving the ideal ore texture for microwave treatment of metalliferous ores. Miner Eng 84:116-129

[48] Chandrasekaran S, Basak T, Ramanathan S (2011) Experimental and theoretical investigation on microwave melting of metals. J Mater Process Technol 211(3):482-487

[49] Liu C, Zhang L, Peng J, Srinivasakannan C, Liu B, Xia H, Zhou J, Xu L (2013) Temperature and moisture dependence of the dielectric properties of silica sand. J Microw Power Electromagn Energy 47(3):199-209

[50] Subasri R, Mathews T, Sreedharan O, Raghunathan V (2003) Microwave processing of sodium beta alumina. Solid State Ionics 158(1):199-204

[51] Katz JD (1992) Microwave sintering of ceramics. Annu Rev Mater Sci 22(1):153-170

[52] Rao K, Ramesh P (1995) Use of microwaves for the synthesis and processing of materials. Bull Mater Sci 18(4):447-465

[53] Bhattacharya M, Basak T (2016) A review on the susceptor assisted microwave processing of materials. Energy 97:306-338

[54] Alford T, Gadre MJ, Vemuri RN, Theodore ND (2012) Susceptor-assisted microwave annealing for activation of arsenic dopants in silicon. Thin Solid Films 520(13):4314-4320

[55] Allan SM, Merritt BJ, Griffin BF, Hintze PE, Shulman HS (2013) High-temperature microwave dielectric properties and processing of JSC-1AC lunar simulant. J Aerosp Eng 26(4):874-881

[56] Gutmann B, Obermayer D, Reichart B, Prekodravac B, Irfan M, Kremsner JM, Kappe CO (2010) Sintered silicon carbide: a new ceramic vessel material for microwave chemistry in single-mode reactors. Chem A Eur J 16(40):12182-12194

[57] Wuchina E, Opila E, Opeka M, Fahrenholtz W, Talmy I (2007) Uhtcs: ultra-high temperature ceramic materials for extreme environment applications. Electrochem Soc Interface $6(4): 30$

[58] T. U. of Arizona's Richard F. Caris Mirror Laboratory (2016) Frequently asked questions about mirror production

[59] Davis JR, Davis JR et al (1993) Aluminum and aluminum alloys. ASM international, Geauga County

[60] Korsch D (2012) Reflective optics. Elsevier Science, Amsterdam

[61] Hecht E (1974) Optics. Addison-Wesley, Boston

[62] Eliasson J, Sandström R (1995) Applications of aluminium matrix composites. In: Key engineering materials. Trans Tech Publications, vol 104, pp 3-36

[63] Taylor LA, Meek TT (2004) Microwave processing of lunar soil. Sci Technol Ser 108:109-123

[64] Danzl R, Helmli F, Scherer S (2009) Focus variation-a new technology for high resolution optical 3d surface metrology. In: The 10th international conference of the slovenian society for non-destructive testing, pp 484-491

[65] Helmli LR (2011) Focus variation instruments in optical measurement of surface topography, vol 14. Springer, Berlin

[66] Kapłonek W, Nadolny K, Królczyk GM (2016) The use of focus-variation microscopy for the assessment of active surfaces of a new generation of coated abrasive tools. Meas Sci Rev 16(2):42-53

[67] Hass G (1955) Filmed surfaces for reflecting optics. JOSA 45(11):945-952

[68] Turkevich AL (1973) Average chemical composition of the lunar surface. Moon 8(3):365-367

[69] Skinner BJ (1979) Earth resources. Proc Natl Acad Sci 76(9):4212-4217

[70] Vinogradov A, Nefedov V, Urusov V, Zhavoronkov N (1972) Esca-investigation of lunar regolith from the seas of fertility and tranquility. In: Lunar and planetary science conference proceedings, vol 3, p 1421

[71] Laul J, Papike J, Simon S (1982) The lunar regolith-comparative studies of the apollo and luna sites. Chemistry of soils from apollo 17, luna 16, 20, and 24. Lunar Planet Sci Conf Proc 12:389-407

[72] Laul J, Rode O, Simon S, Papike J (1987) The lunar regolith: chemistry and petrology of luna 24 grain size fractions. Geochim Cosmochim Acta 51(3):661-673 